\title{
Laser Surface Mapping of the Failed FB-Line Bagless Canister Closure Weld (U)
}

$\frac{\text { Unclassifaed }}{\text { C. E. Sessions CEs }}$

Date:

$12 / 1 / 99$

Authorized Derivative Classifier (ADC)

hestinghouse Savannah River Company

Savannah River Site

Aiken, South Carolina 29808

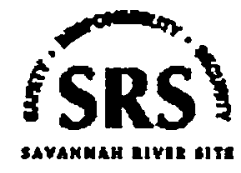

$\diamond$ 


\section{Laser Surface Mapping of the Failed FB-Line Bagless Canister Closure Weld}

by

G. E. Weeks

Westinghouse Savannah River Company

Savannah River Site

Aiken, South Carolina 29808

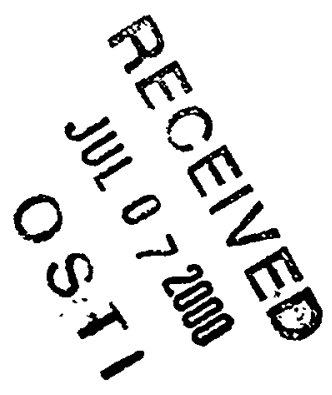

This paper was prepared in connection with work done under the above contract number with the U.S.

Department of Energy. By acceptance of this paper, the publisher and/or recipient acknowledges the U. S.

Government's right to retain a nonexclusive, royalty-free license in and to any copyright covering this paper, along with the right to reproduce and to authorize others to reproduce all or part of the copyrighted paper. 


\section{DISCLAIMER}

This report was prepared as an account of work sponsored by an agency of the United States Government. Neither the United States Government nor any agency thereof, nor any of their employees, makes any warranty, express or implied, or assumes any legal liability or responsibility for the accuracy, completeness, or usefulness of any information, apparatus, product or process disclosed, or represents that its use would not infringe privately owned rights. Reference herein to any specific commercial product, process or service by trade name, trademark, manufacturer, or otherwise does not necessarily constitute or imply its endorsement, recommendation, or favoring by the United States Government or any agency thereof. The views and opinions of authors expressed herein do not necessarily state or reflect those of the United States Government or any agency thereof.

This report has been reproduced directly from the best available copy.

Available for sale to the public, in paper, from: U.S. Department of Commerce, National Technical Information Service, 5285 Port Royal Road, Springfield, VA 22161, phone: $(800)$ 553-6847,

fax: (703) 605-6900

email: orders@ntis.fedworld.gov

online ordering: http://www.ntis.gov/ordering.htm

Available electronically at http://www.doe.gov/bridge

Available for a processing fee to U.S. Department of Energy and its contractors, in paper, from: U.S. Department of Energy, Office of Scientific and Technical Information, P.O. Box 62,

Oak Ridge, TN 37831-0062,

phone: (865)576-8401,

fax: (865)576-5728

email: reportseadonis.osti.gov 


\section{DISCLAIMER}

Portions of this document may be illegible in electronic image products. Images are produced from the best available original document. 
Publication Date: December 2, 1999

\section{Laser Surface Mapping of the Failed FB-Line Bagless Canister Closure Weld (U)}

George E. Weeks 


\section{Contents}

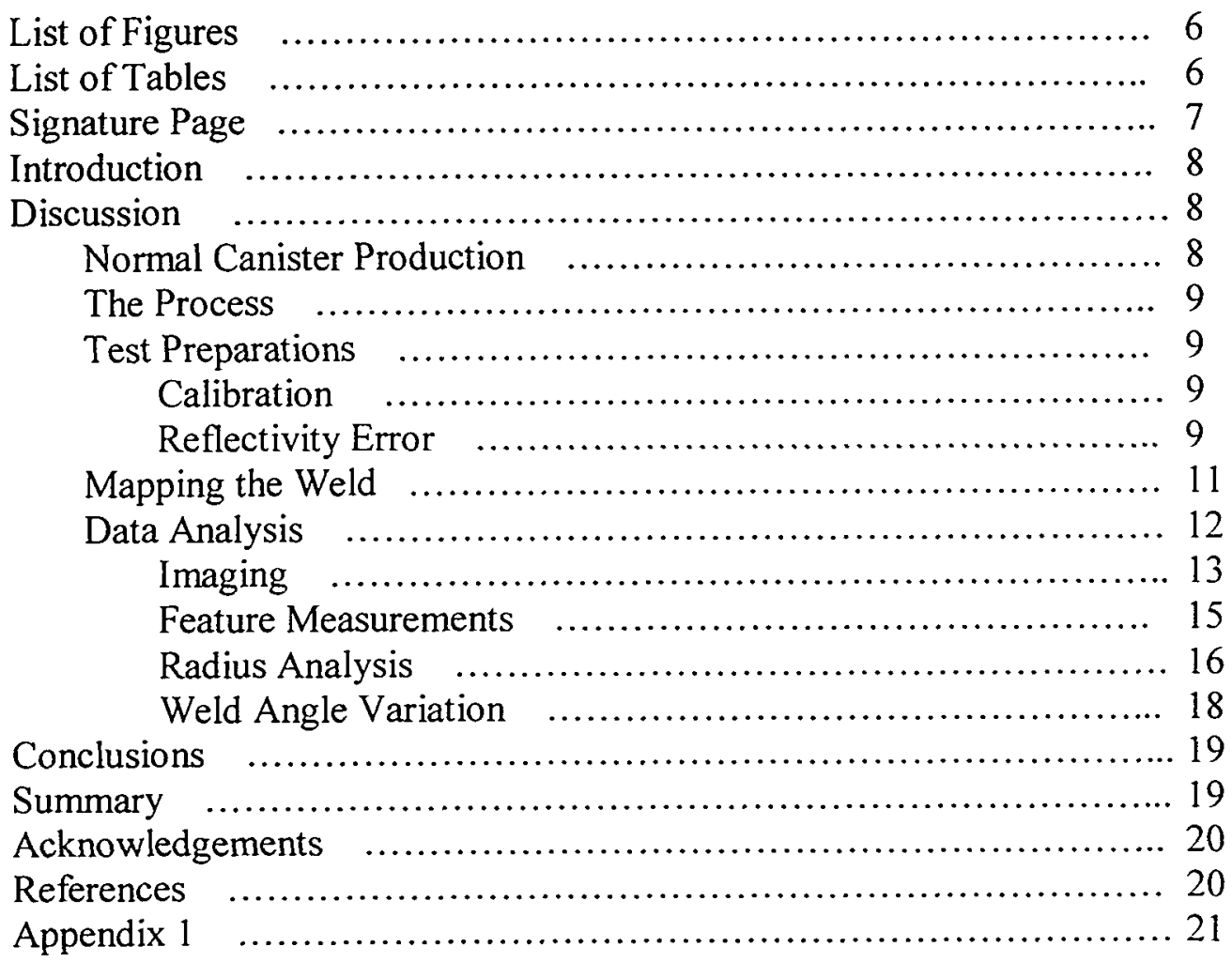




\section{List of Figures}

1. Reflectivity Error Test Apparatus $\quad 10$

2. Laser Surface Mapping Apparatus 11

3. Mapping The Weld 11

4. Comparison Plot 12

5. Difference Plot 12

6. Comparison Plot Magnified 13

7. Weld Video 13

8. Weld Anomaly Area 14

9. Weld Hole - Section 1 14

10. Weld Hole - Section $2 \quad 15$

11. $2^{\text {nd }}$ Tack Location 16

$\begin{array}{ll}\text { 12. Radius Analysis } 1 & 17\end{array}$

$\begin{array}{ll}\text { 13. Radius Analysis } 2 & 17\end{array}$

14. Canister Diameter Variation 18

15. Weld Angle Diagram 18

16. Weld Angle Plot 19

\section{List of Tables}

1. Weld Feature Measurements 15 
W-TRT-A-00002

Title: Laser Surface Mapping of the Failed FB-Line Bugles Canister Closure Weld (U)

Author: George E. Weeks

Project Number:

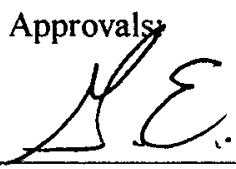

TR \#99-NMSS/SE-021

G. E. Weeks, Author

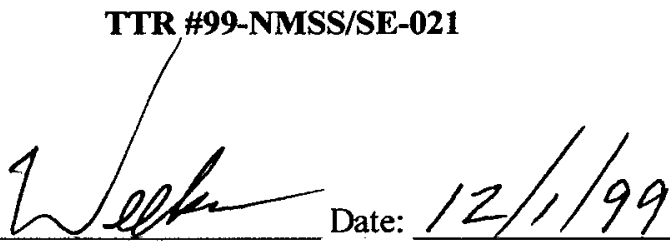

SRTC-Instrumentation and Examination Section

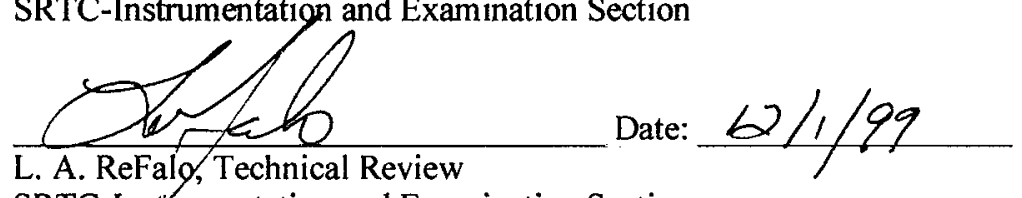

SRTC-Instrumentation and Examination Section

(il) daugherty

Date: 12 ec 99

W. L. Daugherty, Principal Investigator

SRTC-Materials Technology Section

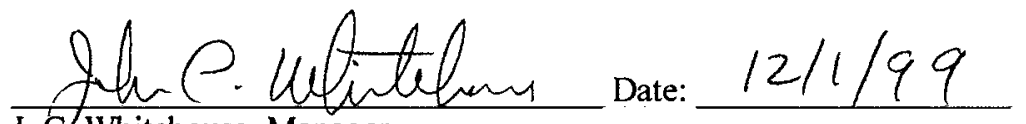

J. C. Whitehorse, Manager

SRTC-Site and New Missions Support

Date: $12 / 1 / 99$

J. A. Mayra, Manager

SRTC-Ihstrumentation and Examination Section

LUis .

Date:

W. I. Lewis III, Deputy Manager

SRTC-Engineered Equipment and Systems Department

Nuclear Materials Stabilization and Storage

Date: $12 / 1 / 99$

Damineflacigh Date: $12-1.99$

1. P. Gray Sr.,

SRTC-Quality Assurance Department 


\section{Laser Surface Mapping of the Failed FB-Line Bagless Canister Closure Weld (U)}

\section{Introduction}

In September of 1999 , seven people were contaminated while doing a routine survey of the F-Area plutonium storage vault. Further investigation of the incident revealed the cause to be a bagless transfer canister with a hole in the closure weld. Westinghouse Savannah River Co. and the Department of Energy launched in-depth investigations.

As a part of these investigations, a detailed evaluation of the failed canister was undertaken. This evaluation was divided into two phases. The first phase was a series of non-destructive evaluations consisting of simple measurements, photography, X-ray imaging, digital radiographic imaging, computer tomographic imaging, and laser surface mapping.

The second phase of the evaluation included techniques that require sectioning the canister and includes metallurgical analysis, and scanning electron microscopy.

This report details the laser surface mapping activity as described in technical task and QA plan 22751TTQAP-LM'.

\section{Discussion}

\section{Normal Canister Production}

A brief description of the bagless canister production is given here in an effort to clarify later descriptions and conclusions. The bagless canister consists of two parts: the can and the plug. The can is a right circular cylinder closed at the bottom. It is 4.6 inches in diameter, 13.87 inches tall, and has a wall thickness of 0.044 inches. There is a small shoulder cut on the inside of the can where the plug is positioned. The wall thickness below the shoulder is 0.060 inches.

The plug is a hollow right circular cylinder closed at the top and bottom. It is 4.507 inches in diameter, 0.75 inches tall, and has a wall thickness of 0.120 inches. There is a screw fitting in the top center of the plug to attach the positioning rod.

With the can inserted into the glovebox sphincter seal, product is inserted. The plug is then positioned on the shoulder inside the can. The can is back-filled with helium and welded closed.

The Tungsten Inert Gas (TIG) welding process is used to close the canister. In this application, no filler metal is used. The canister is clamped in place and the TIG electrode is moved around the outside of the canister. Before the continuous weld is started, three tacks are done approximately 90 degrees apart. The continuous weld starts approximately 90 degrees from the third tack weld and continues for 15 inches (canister circumference is about 14.4 inches) providing a 0.6 inch overlap. The welder then ramps down for 1.06 inches and the welding process is complete.

After the canister has been welded, it is cut using a rolling wheel cutter similar to a tubing cutter. The cut is done in the center of the weld. The cut separates the completed bagless canister from the stub. The stub stays in the bagless glovebox and provides the containment seal. 


\section{The Process}

A detailed discussion of the methods and equipment used in surface mapping the canister will not be given in this report. This information is proprietary. However, in general, the surface map is generated using a laser to measure the distance to the surface of the canister as it is rotated.

The distance measurements are very precise with resolution to approximately 0.2 microns. Based on the calibration data generated at the SRTC Standards Lab, with $95 \%$ confidence, the accuracy of these distance measurements is within $+/-10$ microns.

\section{Test Preparations}

A series of tests had to be performed with the surface mapping equipment prior to mapping the failed canister. The mapping equipment was originally developed to provide unique identification of canisters stored in the Actinide Packaging and Storage Facility.

This is the first time laser surface mapping has been applied to non-destructive examination. As a result, several operating parameters of the mapping system had to be modified. These parameters defined the size of the canister to be mapped, as well as the resolution and range of the mapping operation.

Operation of the system was verified by mapping a surrogate canister several times and using comparison software that was designed for canister identification to measure the repeatability of the mapping operation.

The failed canister was cut in half to remove the product. After this operation the canister was no longer tall enough for the mapping system to work properly. It was necessary to build a small platform to hold the canister at the proper height. It was also necessary to join the canister to the platform using a piece of foam that was cut to fit the inside diameters of the canister and the platform.

\section{Calibration}

The mapping system is a prototype that had never been placed in field operation prior to this time. It was necessary to have the laser displacement sensor calibrated by the SRTC Standards Lab. The results of the calibration are located in Job Folder 22751, or can be obtained from the standards lab by referencing M\&TE 3-2639².

\section{Reflectivity Error}

The Laser Displacement Sensor (LDS) was designed for use on diffuse surfaces. Based on difficulties encountered during its calibration, there was concern that the reflectivity of the canister surface could cause increased variability'.

The LDS was taken to the Coherent Optical Measurements Lab (M. Pechersky) of the Material Technology Section to quantify the error caused by canister surface reflectivity. A three dimensional micrometer stage was used to precisely move the LDS with respect to the surface of a surrogate canister. Figure 1 below is a picture of the test apparatus. 


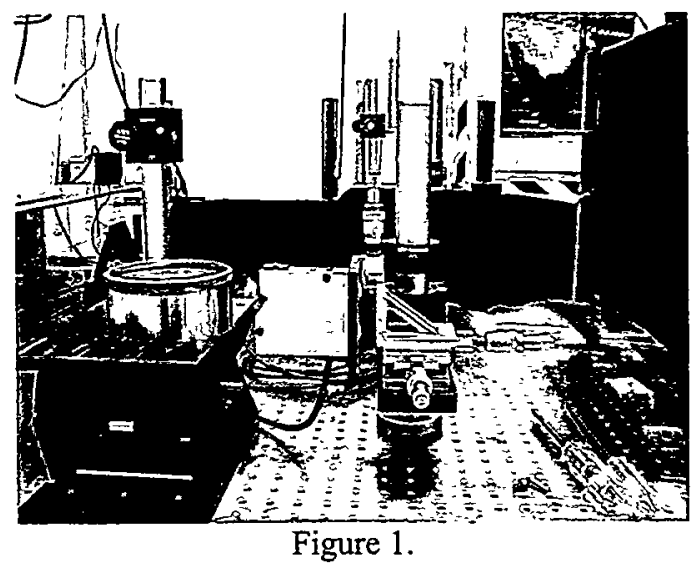

This test was not intended to be a rigorous calibration, but rather a characterization of the variability introduced by the reflectivity of the canister surface. The test was done with the laser pointed at the center of the weld surface. Measurements were taken every $0.0100 \mathrm{~mm}$ over a range of $0.1000 \mathrm{~mm}$. Four segments of the instrument range were tested; the segment ranges are listed below:

$0.0000 \mathrm{~mm}$ through $0.1000 \mathrm{~mm}$, $1.5000 \mathrm{~mm}$ through $1.4000 \mathrm{~mm}$, $1.5000 \mathrm{~mm}$ through $1.6000 \mathrm{~mm}$, and $-1.5000 \mathrm{~mm}$ through $-1.4000 \mathrm{~mm}$.

In each test segment, the micrometer stage was zeroed with the LDS. During these tests, the LDS and micrometer stage agreed to within 2.5 microns and measurement variation was observed to be $+/-0.2$ microns. Similar tests were done using a black target over range segments from $0.0000 \mathrm{~mm}$ to $2.5000 \mathrm{~mm}$ with similar results.

These tests clearly showed that the surface reflectivity did not adversely impact the precision of the surface map.

At the conclusion of the apparatus validation tests described above, an SMI-51 safety inspection was completed and documented by M. T. Hubbard and G. E. Weeks. The SMI- 51 and Conduct of R\&D safety checklist can be located in Job Folder 22751.

A Job Hazards Analysis (JHA) was conducted on October 12, 1999, and is documented in SRT-LWP-99$00147^{3}$. As a result of the JHA, there was an unresolved question as to whether laser energy would liberate plutonium oxide from the surface of the canister. This was treated as an Unreviewed Safety Question (USQ). A screening USQ was conducted and is documented in SRT-USQ-99-0134 ${ }^{4}$. The consensus of the USQ evaluation team was that the laser would not liberate enough of plutonium oxide to challenge the design basis of the hood.

Upon resolution of all safety concerns, the mapping apparatus was installed in the radiological hood in $773-$ A, room B126. Figure 2 shows a picture of the mapping apparatus after installation. 


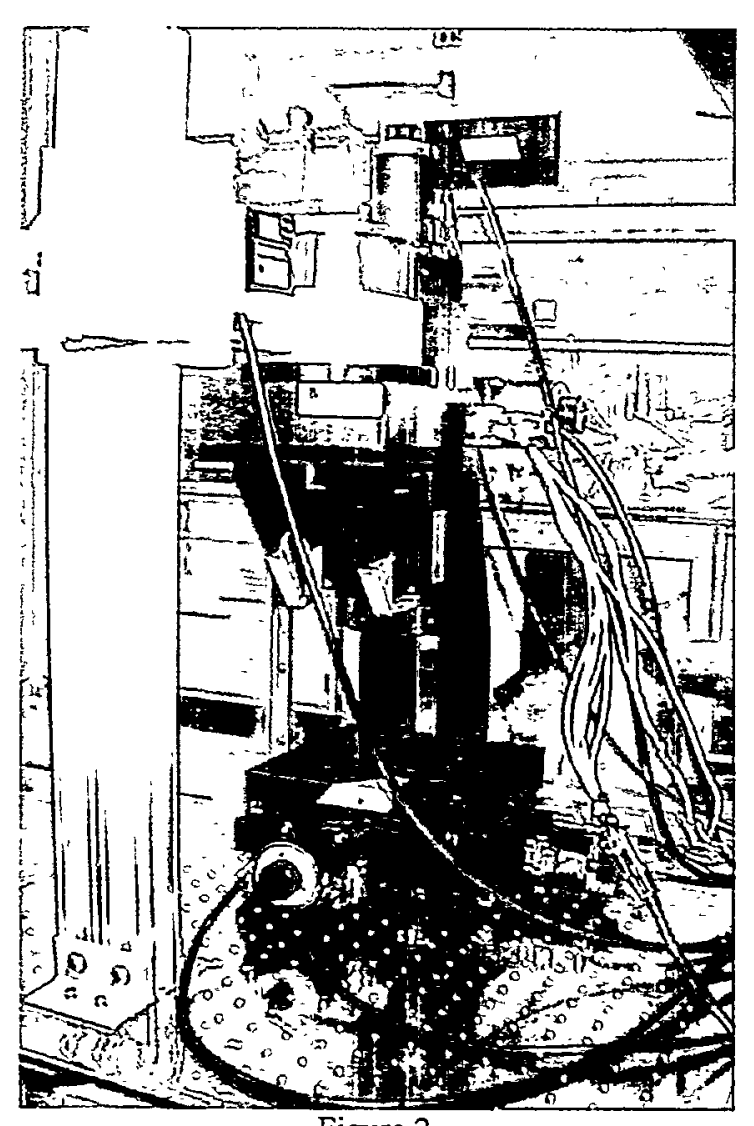

Figure 2.

\section{Mapping the Weld}

The weld mapping was done on October 14, 1999. Three independent maps were made. Figure 3 shows the actual canister during the mapping process.

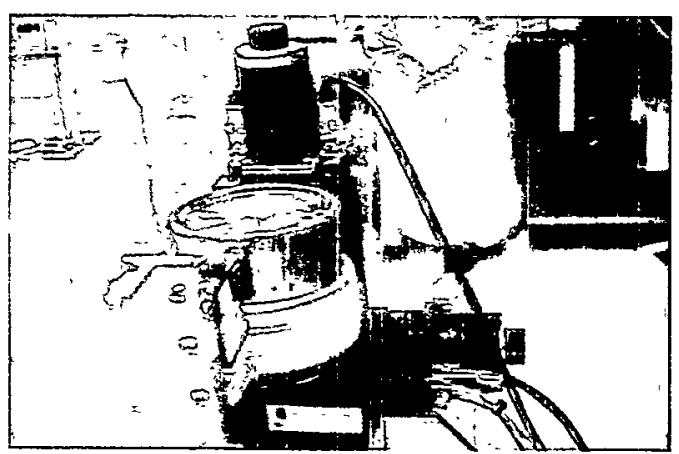

Figure 3.

There are a series of 150 segments in each map. Each segment is comprised of 7200 measurements of the distance variation between the LDS and the canister surface at one elevation over one 360-degree revolution. Each map segment is separated from its neighbors by 50 microns. Therefore, the top $7.5 \mathrm{~mm}$ of the canister was mapped with a resolution 50 microns by 50 microns in the $\mathrm{x}$ and $\mathrm{y}$ planes and 1 micron in the $\mathrm{z}$ plane. 


\section{Data Analysis}

Using map comparison software developed for canister identification, ten randomly selected segments from each of the three maps were compared. The results show that comparable segments between any two maps repeat with a RMS difference of less than 5 microns and correlate to better than 0.99 (on a scale from 0-1). Figure 4 shows the output of the comparison software for a typical map segment.

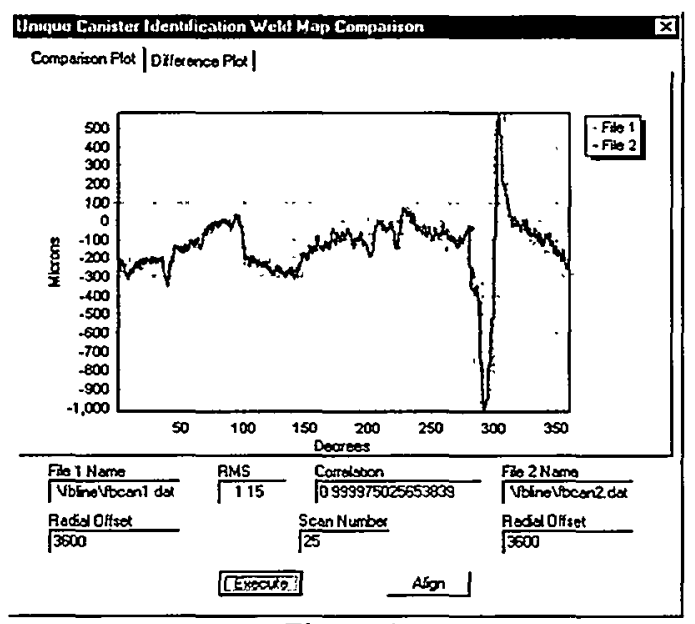

Figure 4.

Figure 5 shows a plot of the difference between the two map segments. As can be seen, the difference is largely random. This implies that noise and not a systematic difference introduced the error.

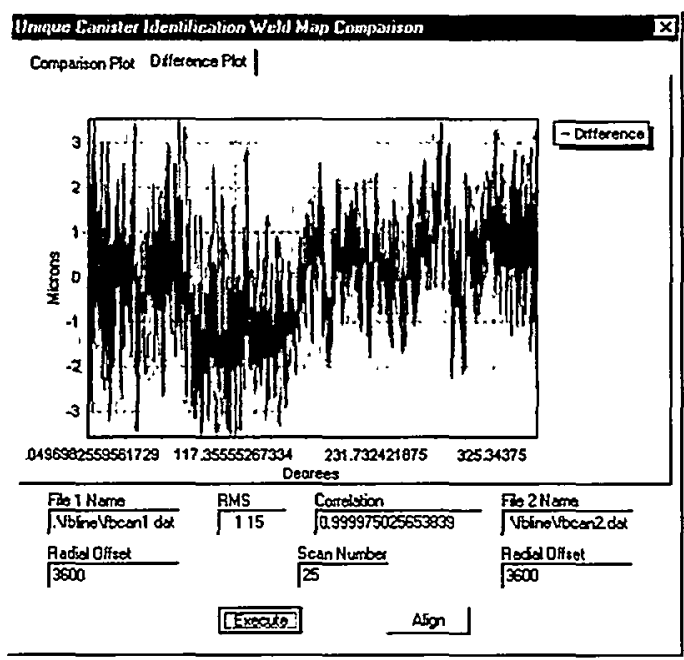

Figure 5.

Even though a single line appears in Figure 4, two lines are actually displayed. The two lines are so nearly the same that the difference cannot be discerned at that magnification. Figure 6 shows a portion of the same plot magnified 33 times on the $\mathrm{X}$-axis and 17 times on the $\mathrm{Y}$-axis. As before, the two plots are nearly indistinguishable. 


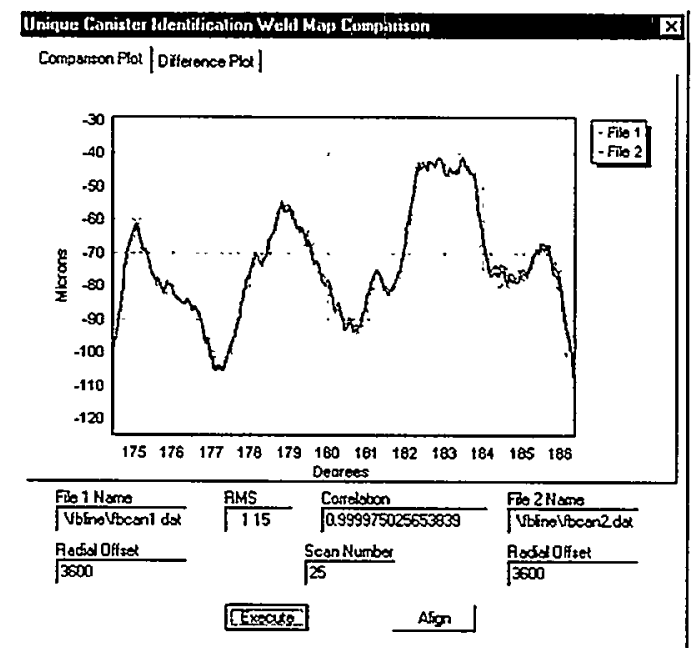

Figure 6.

\section{Imaging}

Using the Interactive Data Language, three-dimensional images of the data were generated and joined together into a "video clip". Electronic copies of this report can play the clip by double clicking on Figure 7 (a mpeg player must be installed on the computer). The orientation of the canister in the figure is as follows.

The bottom of the gray area in the image represents the top of the canister. The rolled over edge is the cut surface on the top of the canister. In this view the bottom of the canister is tilted up and away from the reader at a 45-degree angle. There is a significant loss of image resolution in the paper due to compression.

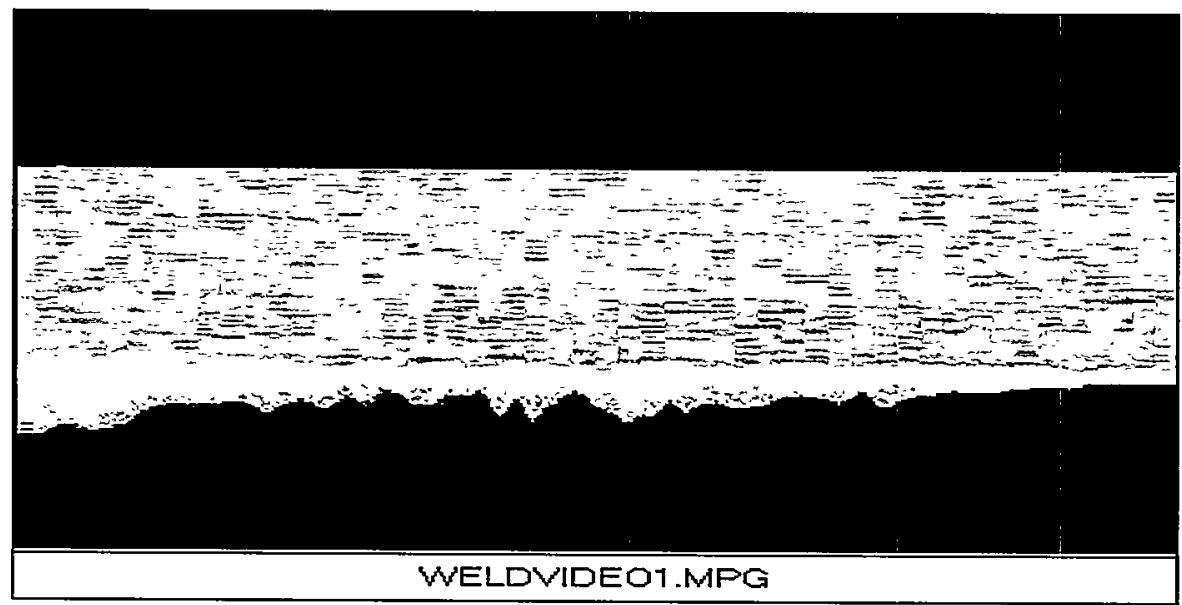

Figure 7.

An equivalent set of images is attached in Appendix 1.

These images were used to locate features of interest on the weld (e.g. tack locations and the continuous weld start/stop location) and to examine the physical characteristics of the hole in the weld. 


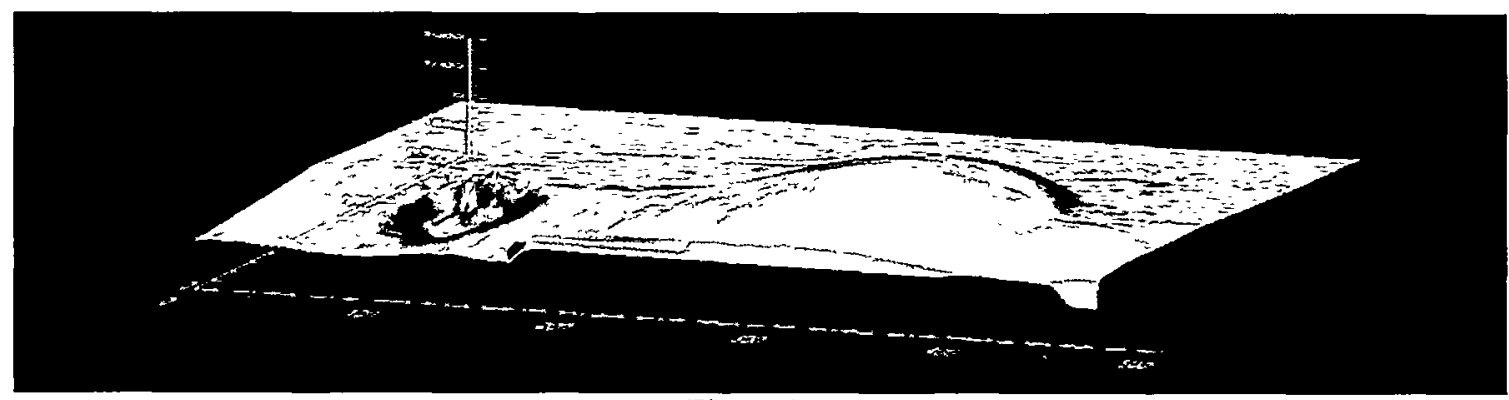

Figure 8.

Figure 8 shows the area of the second tack weld. The hole and an adjacent globule in the weld are clearly visible. The weld line of the continuous weld is visible across the globule, indicating that it was present before the continuous welding process, and therefore, was created during the tack. (Previous visual observations identified that the hole and globule are at the location of the second tack.) The volume of the globule is significantly larger than the volume of the hole. This suggests a corresponding loss of material in the upper half of the weld where the canister was separated from the stub. From this picture, it is clear the weld anomaly occurred during the second tack of the welding process.

Figure 9 is a horizontal cross-section looking from the center of the hole toward the top of the can.

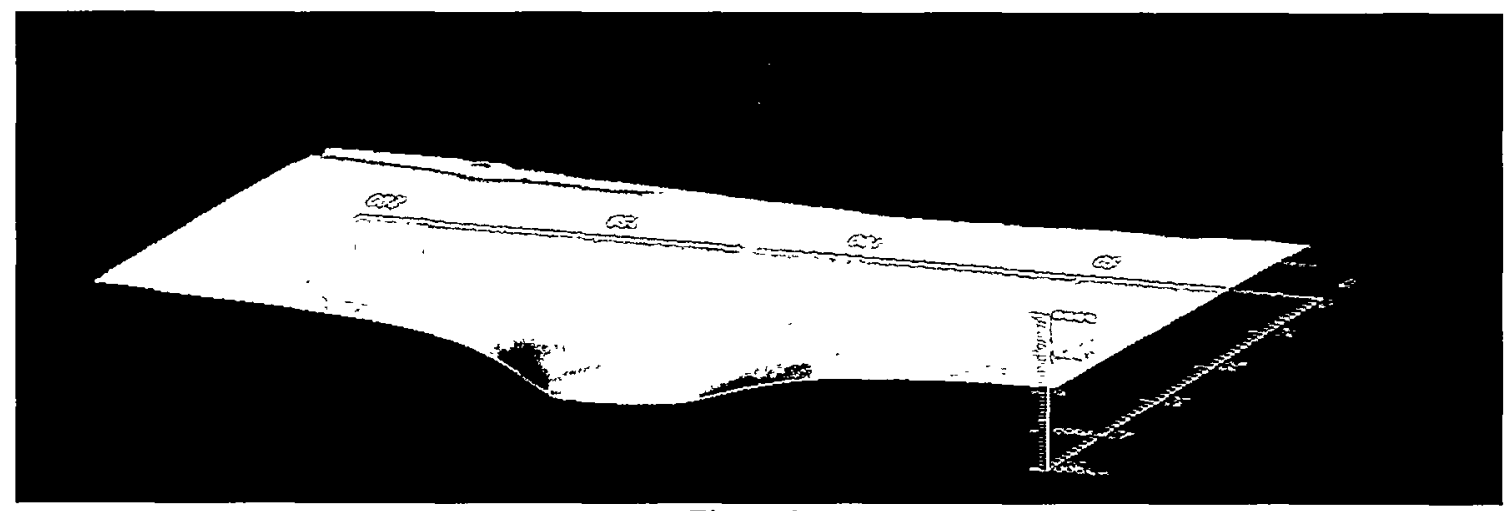

Figure 9.

From the smooth transition of the weld surface to the plug surface it appears that this portion of the weld fused to the plug. The smooth side of the hole suggests that the hole was not sealed from the outside with material that was physically attached to the hole. This will be verified by scanning electron microscopy. Figure 10 shows the same cross-section of the hole viewed from the center of the hole toward the bottom of the canister. 


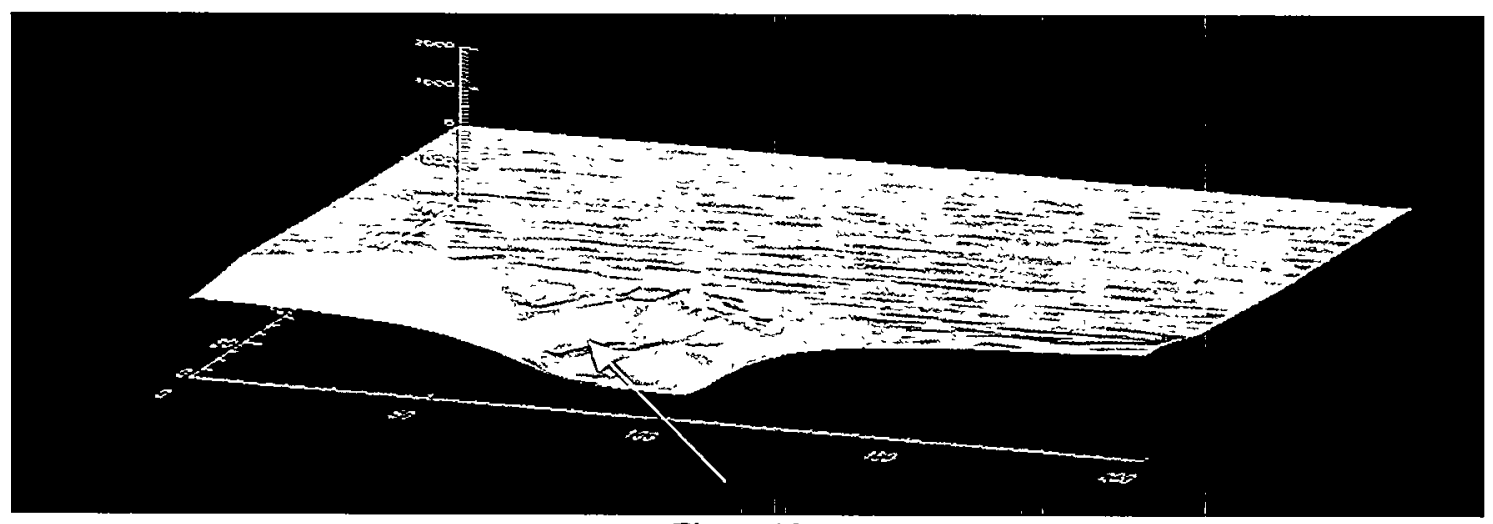

Figure 10.

The arrow marks a section of the weld that did not fuse to the plug.

\section{Feature Measurements}

The map data can be used to make measurements of weld features. Table 1 contains measurements of the tacks and the start and stop points of the continuous weld. The reference point for these measurements is the top dead center of the canister when the plug identification stamp is located horizontally and is readable from left to right.

Interpreting the weld map to locate these features is an inexact science at best and relies on the interpretation of experienced weld engineers. Table 1 shows the measured lengths of these features as compared to the lengths programmed into the welder. The difference between the measured and programmed location for each feature is considered to be within experimental error.

\begin{tabular}{|c|c|c|c|c|}
\hline Feature & \begin{tabular}{|l|} 
Location \\
(deg.)
\end{tabular} & \begin{tabular}{|l|} 
Length \\
(deg.) \\
\end{tabular} & \begin{tabular}{|l|} 
Length \\
in.)
\end{tabular} & \begin{tabular}{|l|} 
Program \\
Length \\
in.) \\
\end{tabular} \\
\hline 1st Tack & 155 & 22.5 & 0.903 & 0.9 \\
\hline Between 1st and 2nd tack & 132.5 & 58 & 2.328 & 2.4 \\
\hline 2nd Tack & 74.5 & 22.5 & .903 & 0.9 \\
\hline Between 2nd and 3rd tack & 52 & 74.5 & 2.991 & 2.88 \\
\hline 3rd Tack & 337.5 & 22.5 & 0.903 & 0.9 \\
\hline Between 3rd tack and start & 315 & 60.5 & 2.428 & 2.88 \\
\hline Start/Stop & 254.5 & 43.5 & 1.746 & 1.69 \\
\hline Between stop and 1st tack & 211 & $\underline{\underline{56}}$ & 2.248 & $\underline{1.9}$ \\
\hline Total & & 360 & 14.45 & 14.45 \\
\hline
\end{tabular}

In the case of the second tack, the start and stop locations were difficult to define due to the globule and the hole in the tack area. Initial observations located the beginning of the $2^{\text {nd }}$ tack at 77.5 degrees. Examination with the Scanning Electron Microscope (SEM) located an exposed portion of the second tack beginning at 74.5 degrees. The actual start of the second tack is likely between 74.5 and 77 degrees. Figure 11 shows the map of the second tack, from 80 to 50 degrees. Examining the image in Figure 11 closely, a faint flow line can be seen below the continuous weld line indicating a portion of the tack. 


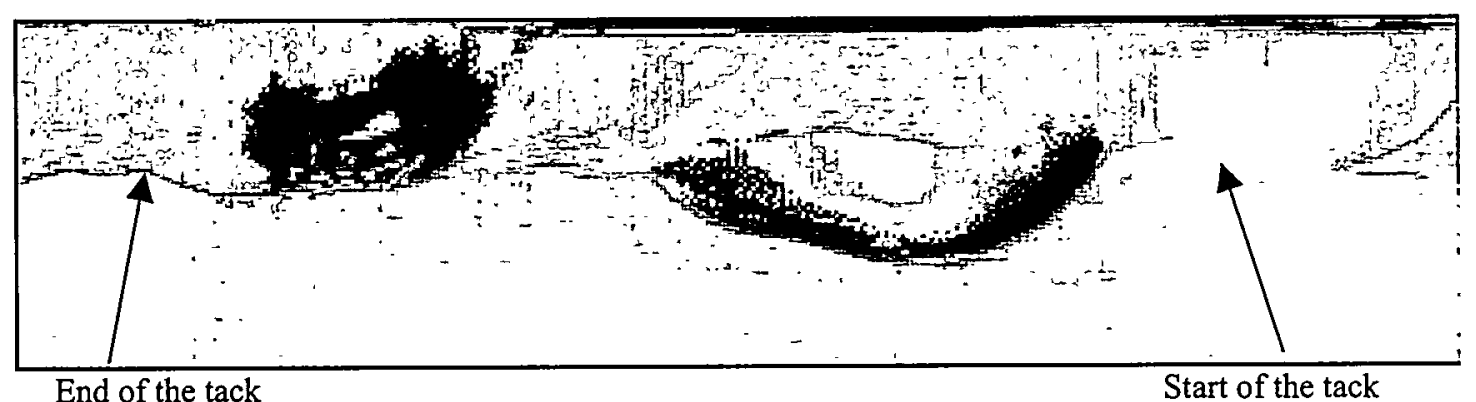

Figure 11.

The arrows show the currently accepted beginning and ending of the tack as identified by the SEM and corroborated by the laser mapping data. Locating the tack at this point also provides a better match with the welder's programmed location.

Since the surface map is an array of distances referenced to the surface of the canister, the depth of the hole can be measured by simply reading the deepest point in the region of the hole. The deepest point in the hole is $1.435 \mathrm{~mm}$. Using a similar technique, the height of the globule was measured as $1.700 \mathrm{~mm}$.

An estimate of the volume of the hole and globule can de determined by summing the distances in the map array over the regions of interest and then multiplying by the differential element size of $0.0025 \mathrm{~mm}^{2}$. While this method is not exact, it is sufficiently accurate due to the small differential element size. The volume of the hole is approximately $13.4 \mathrm{~mm}^{3}$ and the volume of the globule is approximately $51.9 \mathrm{~mm}^{3}$.

These volumes are referenced to the can OD surface. Since the weld bead is typically concave due to the can/plug gap, the hole is actually smaller and the globule is larger than these volumes indicate.

\section{Radius Analysis}

During the mapping process, it is not possible to place the centerline of the canister precisely on the centerline of the motion stage. This lack of centering, however slight, is measured by the LDS and must be removed from the map data. The algorithm for removing this error requires that the concentricity error be measured and recorded.

The variation in radius can be measured by subtracting a sine wave of the proper phase and magnitude from the measured concentricity of the canister. This analysis was done at a point approximately 0.5 inches below the weld and at another point immediately below the weld. Figures 12 and 13 show the variation in radius with the locations of the tack welds overlaid on the radius plot.

This analysis of the canister radius was performed to determine whether the weld anomaly could have been caused by excessive distance between the canister wall and the plug. Clearly, the welding process forever alters the state of the canister from the time of the second tack. We can only measure what is present and attempt to infer what might have been prior to the welding operation.

There is no evidence to support the hypothesis that a large gap existed between the can wall and the plug. Figures 12 and 13 show the radius variation to be on the order of 250 microns just below the weld, and about 120 microns at a point 0.5 inches below the weld. In both cases, the radius variation at the failed tack (marked by arrows on both plots) is significantly less than over the rest of the canister. 


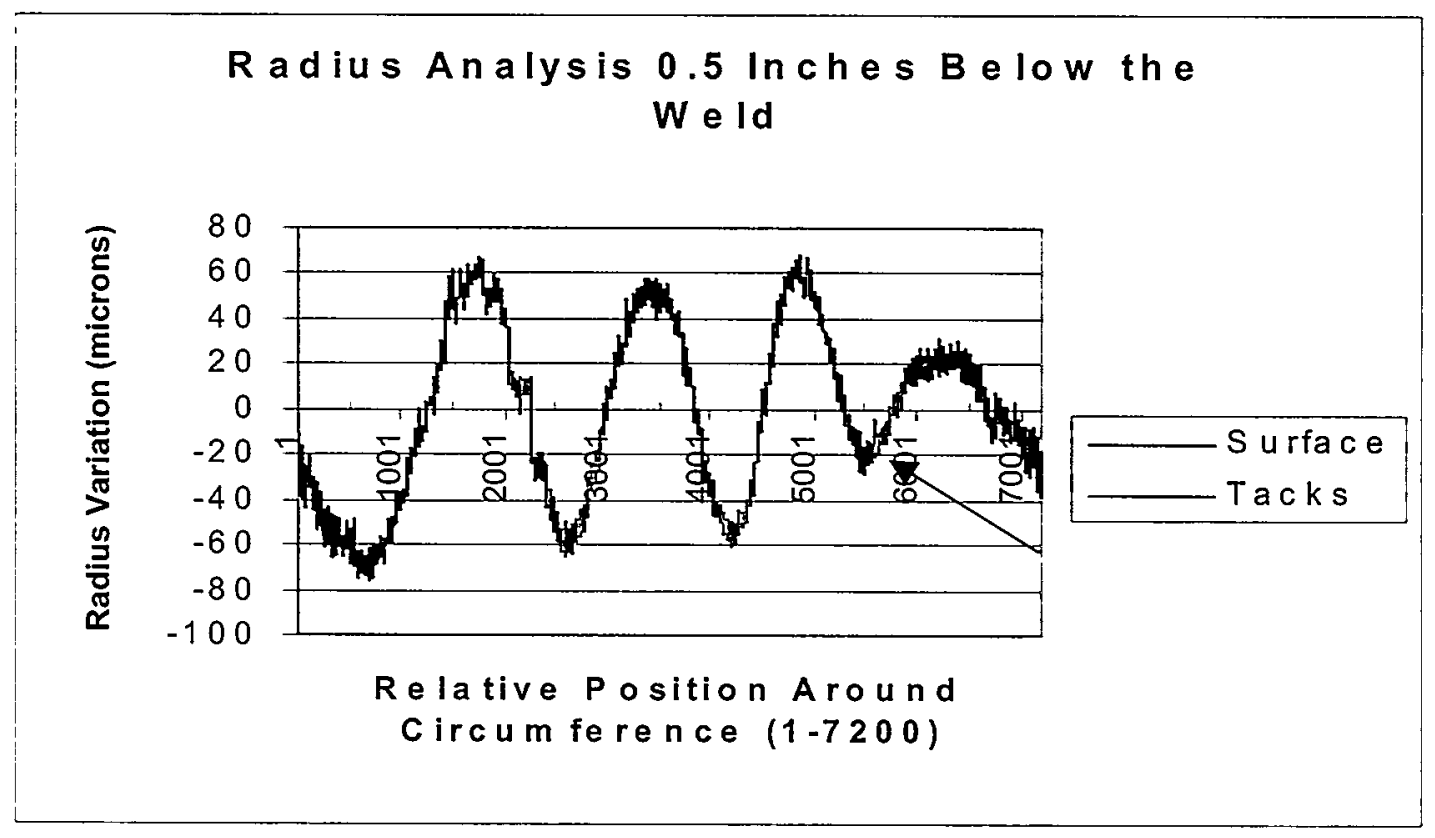

Figure 12.

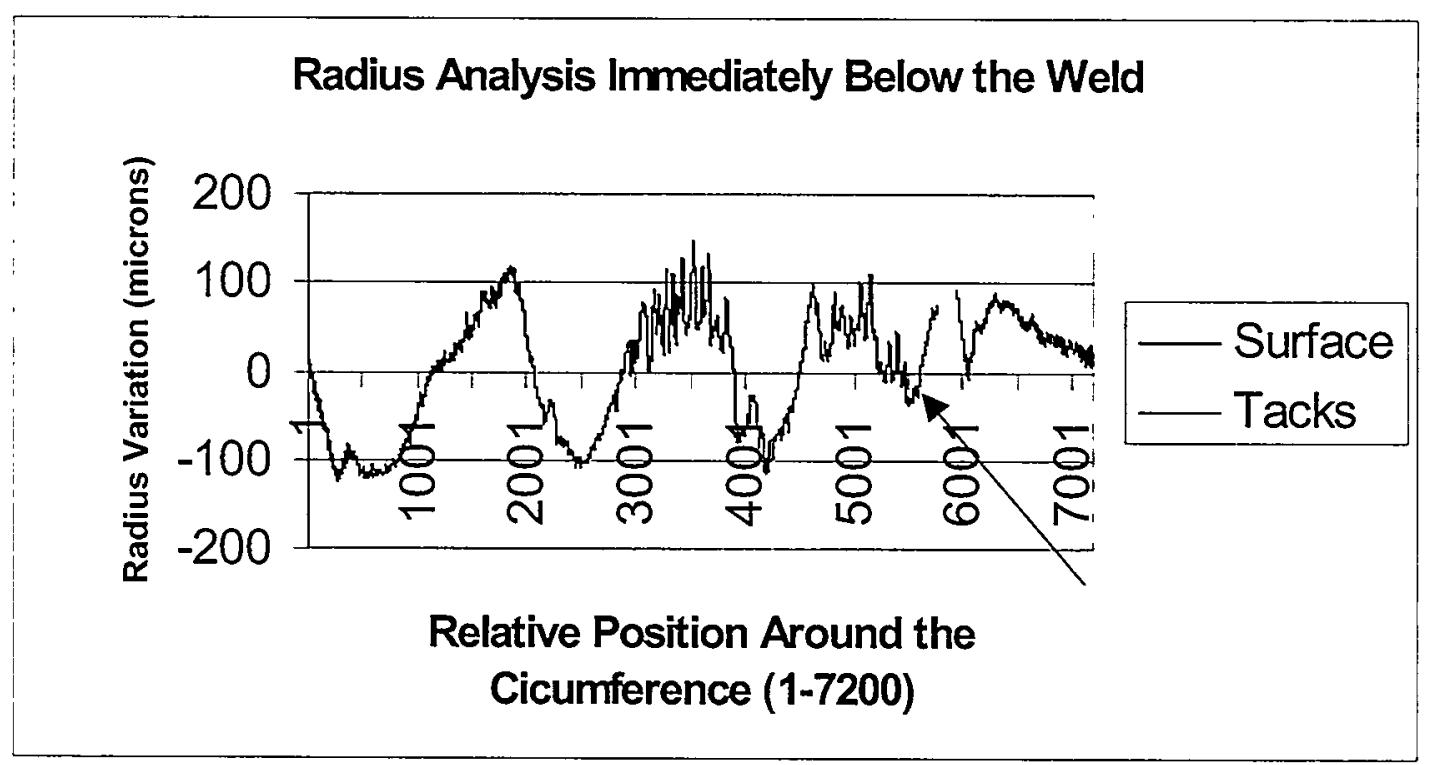

Figure 13.

Variation of the canister diameter is calculated by adding the radius variations of points exactly opposite from each other. Figure 14 is a plot of the variation in the canister diameter at 0.5 inches below the weld. 


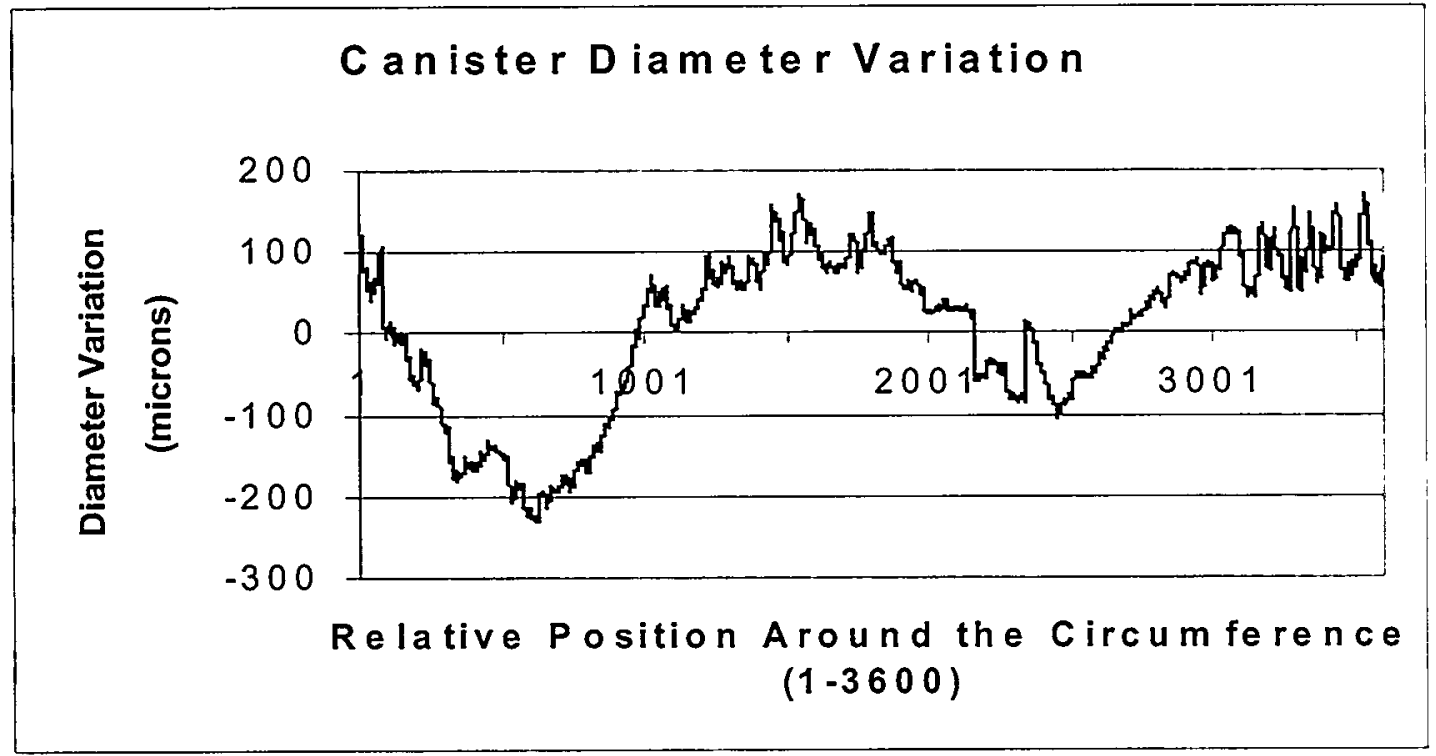

Figure 14.

The canister diameter varies over a range of approximately $+/-200$ microns.

\section{Weld Angle Variation}

The normal welding process generates a concave surface along the weld. Visual inspection of the weld noted a small bulge that coincided with a change in the angle of the weld surface with respect to the canister wall. This bulge is located at the end of the $3^{\text {rd }}$ tack (from $400-850$ along the $x$-axis in Figures 12,13 , and 16). To quantify this observation, an estimate of the angle of the surface of the weld was made. This estimate was calculated by selecting a reference point on the can wall just below the weld and a second reference point at the top of the can. The angle is calculated using equation 1 below:

$$
\Theta=\operatorname{Tan}^{-1}\left(\left(x_{w}-x_{r}\right) / y\right)
$$

Where:

$\Theta$ - the angle between the weld surface and the canister wall.

$\mathrm{x}_{\mathrm{w}}$ - the horizontal distance to the weld surface at the top of the canister.

$\mathrm{x}_{\mathrm{r}}$ - the horizontal distance to the reference point on the canister wall below the weld.

$y-$ the vertical distance between $x_{w}$ and $x_{r}$, in this case 6000 microns).

Figure 15 shows how the angle $\Theta$ relates to the canister wall.

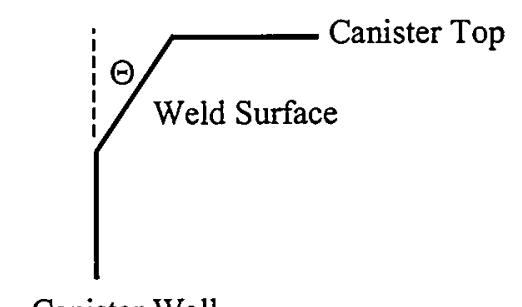

Canister Wall

Figure 15. 
Figure 16 is a graph of the weld angle for each point around the weld. In the areas where the weld angle is positive, the weld bead is concave (i.e. it angles into the center of the canister). In the areas where the weld angle is negative, the weld bead is convex (i.e. it angles out away from the canister). It is interesting to note that, with one exception, the tack areas angle outward while most of the weld angles in toward the center of the can. The bulge on the third tack is marked with an arrow.

\section{Angle from the Wall of the Can to the We Id Surface}

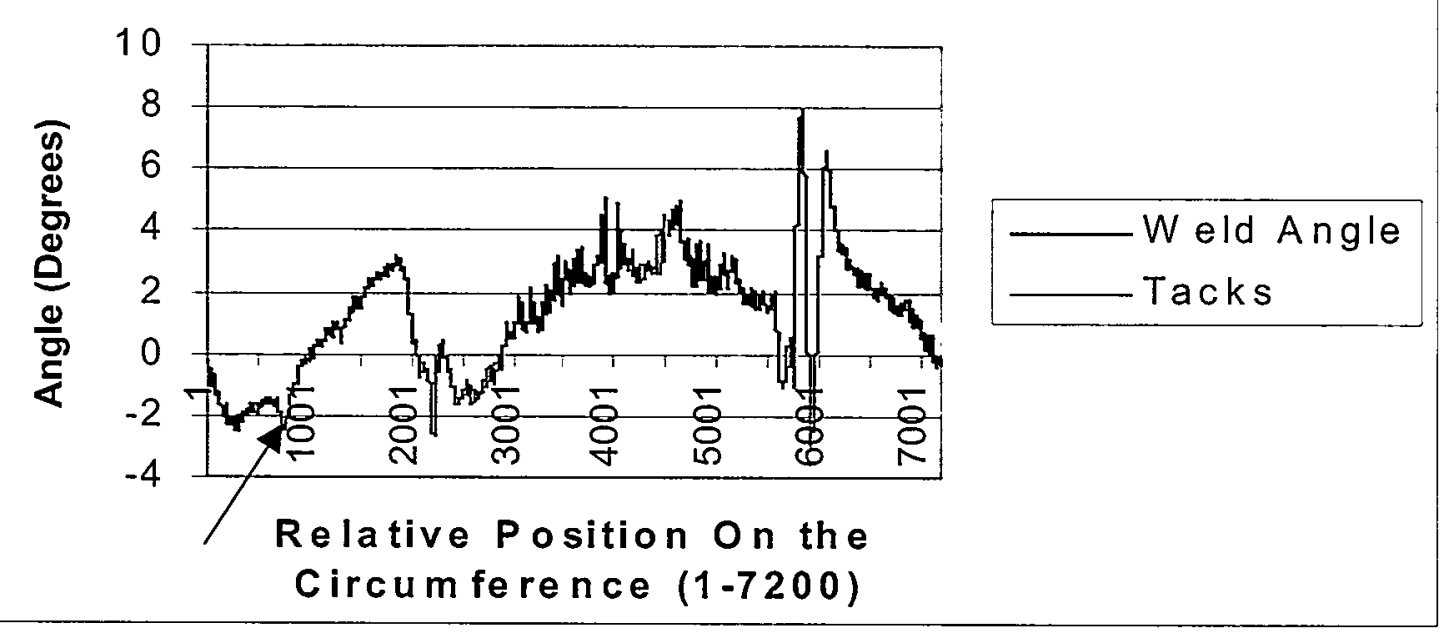

Figure 16.

This analysis was repeated using the last segment of the map as the reference. There was no significant change in the results.

\section{Conclusions}

- The weld anomaly began during the second tack.

- The hole is $1.435 \mathrm{~mm}$ deep with a volume of $13.4 \mathrm{~mm}^{3}$, referenced to the canister surface.

- The globule is $1.700 \mathrm{~mm}$ tall with a volume of $51.9 \mathrm{~mm}^{3}$, referenced to the canister surface.

- Excessive metal in the globule suggests that similar weld problems may be found in the stub that the canister was cut from. The stub is used to maintain the seal integrity of the bagless glovebox.

- The laser mapping data suggests that the hole was not sealed from the outside with material that was physically attached to the hole.

- Based on the radius analysis, excessive distance between the canister wall and the plug was not the cause of the weld anomaly of the $2^{\text {nd }}$ tack.

\section{Summary}

A laser surface map of the failed FB-Line bagless canister closure weld was made and proved to be useful in the examination of the weld anomaly. The map was used to generate detailed three-dimensional images of the closure weld, locate and make physical measurements of weld features, measure variations in the canister radius, and estimate the angle between the weld and the canister wall. 


\section{Acknowledgements}

The author wishes to acknowledge the Subgroup on Safeguards Technical Support and Brookhaven National Laboratory International Safeguards Project Office for funding the development of the laser surface mapping system, and generously releasing the mapping apparatus for use in this study.

\section{References}

' 22751-TTQAP-LM, Task Plan for Failure Analysis Activities on the FB-Line Failed Bagless Transfer Canister -Weld Defect Surface Mapping (U) Rev. 0, G. E. Weeks, September 29, 1999.

${ }^{2}$ M\&TE 3-2639, Certificate of Calibration for M\&TE 3-2639 (U), C. P. Reeve, October 1999.

${ }^{3}$ SRT-LWP-99-00147, Job Hazard Analysis (JHA) for the Laser Displacement Mapping of the FB-Line Canister (U), D. T. Hobbs, G. E. Weeks, H. L. Thacker, October 12, 1999.

${ }^{4}$ SRT-USQ-99-0134, Laser Displacement Mapping of FB-Line Canister (U), F. Fondeur, R. F. Swingle II, October 14, 1999. 


\section{Appendix 1}

This appendix contains images that depict the complete circumference of the failed canister weld. The figure and table show the circumference of the canister and the relative locations of the images, tacks. and the continuous start/stop.

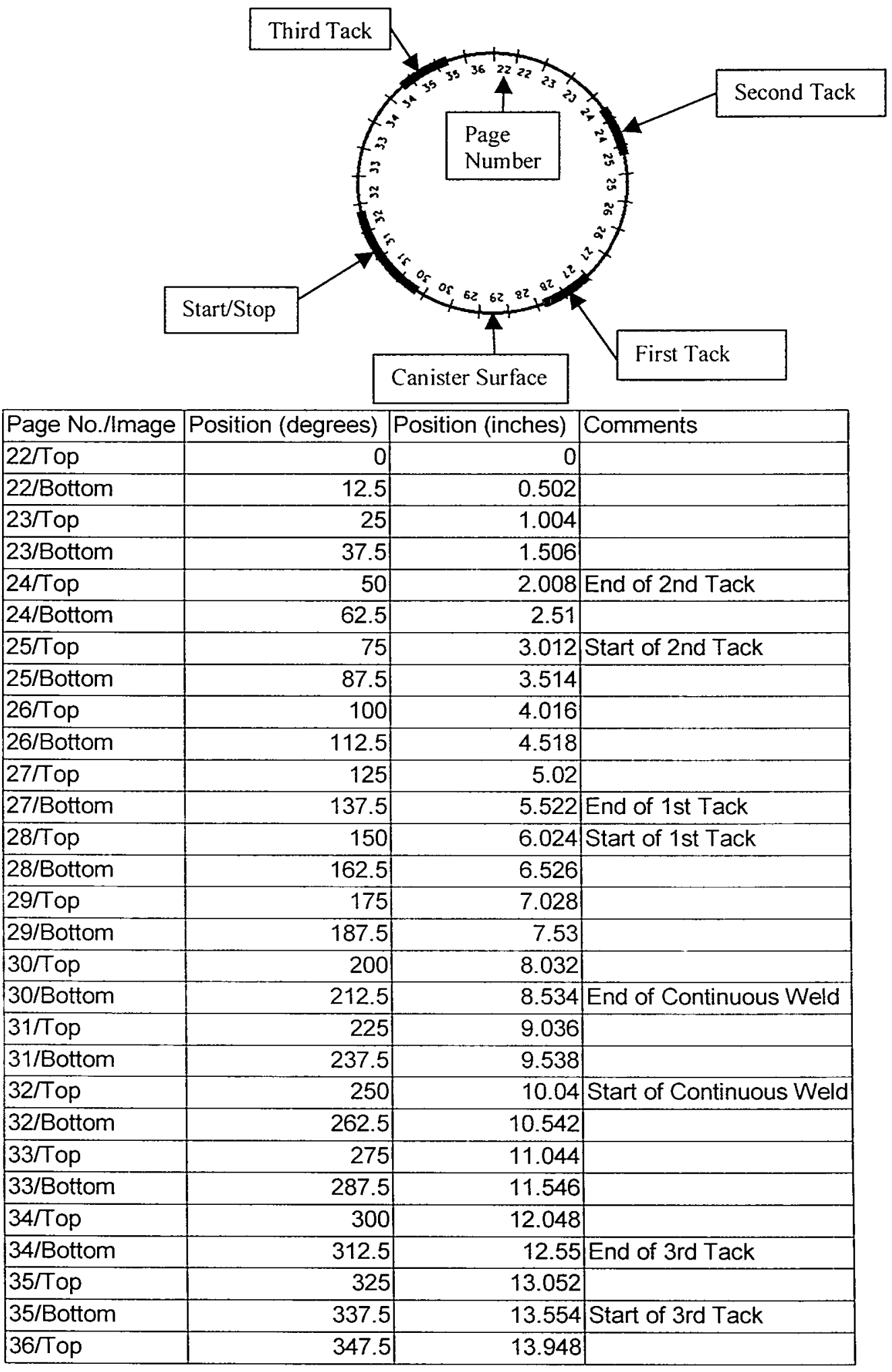



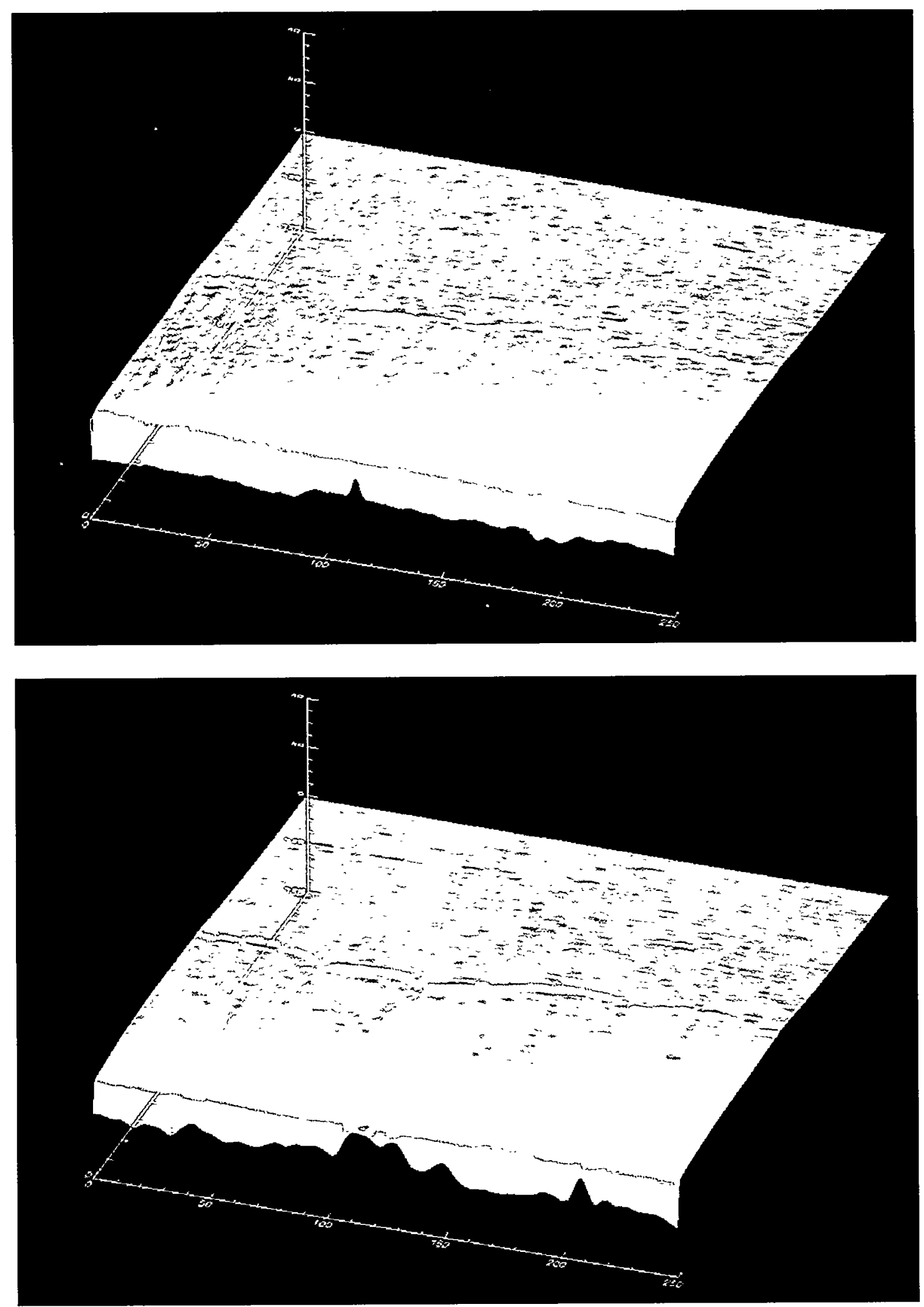

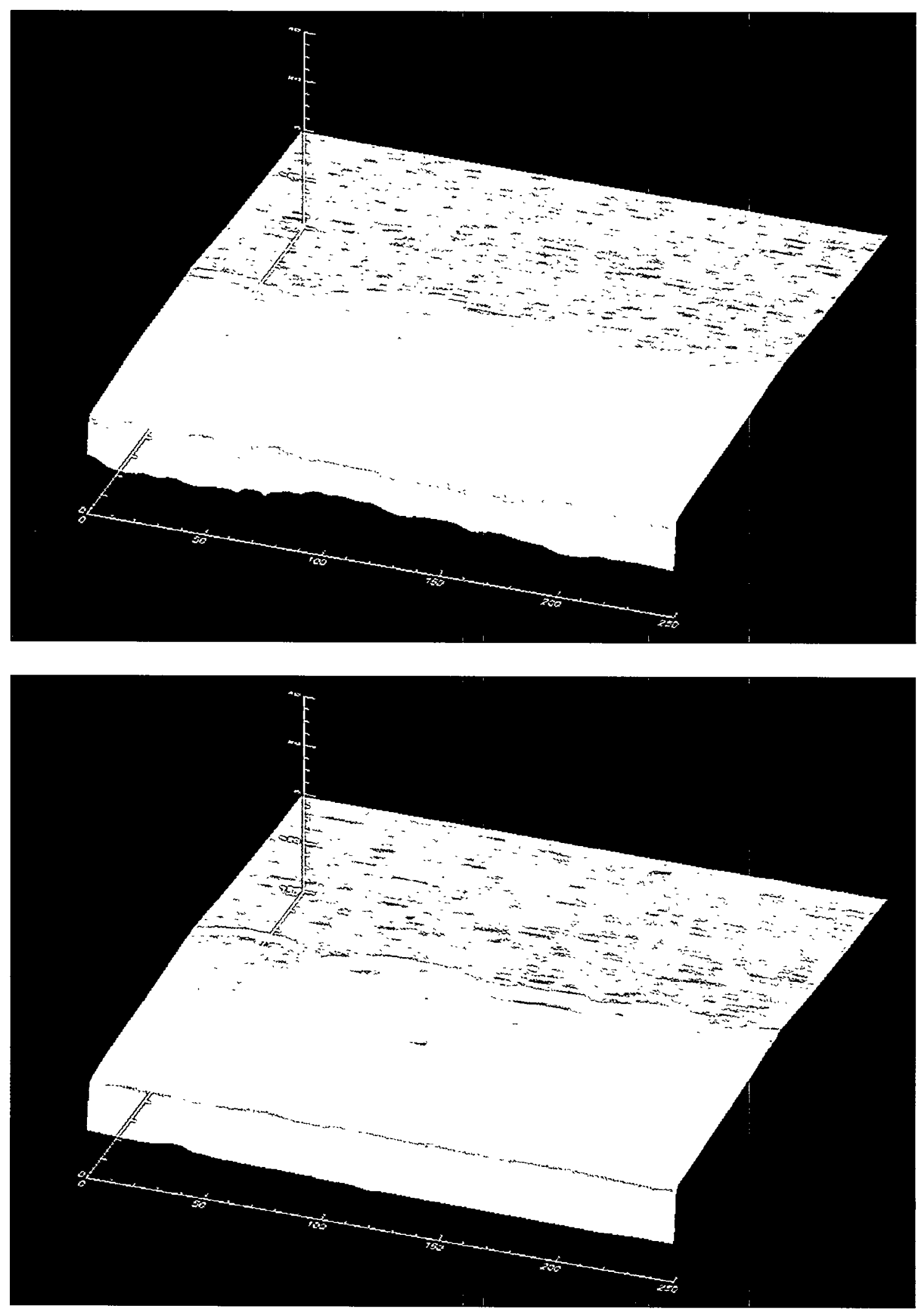

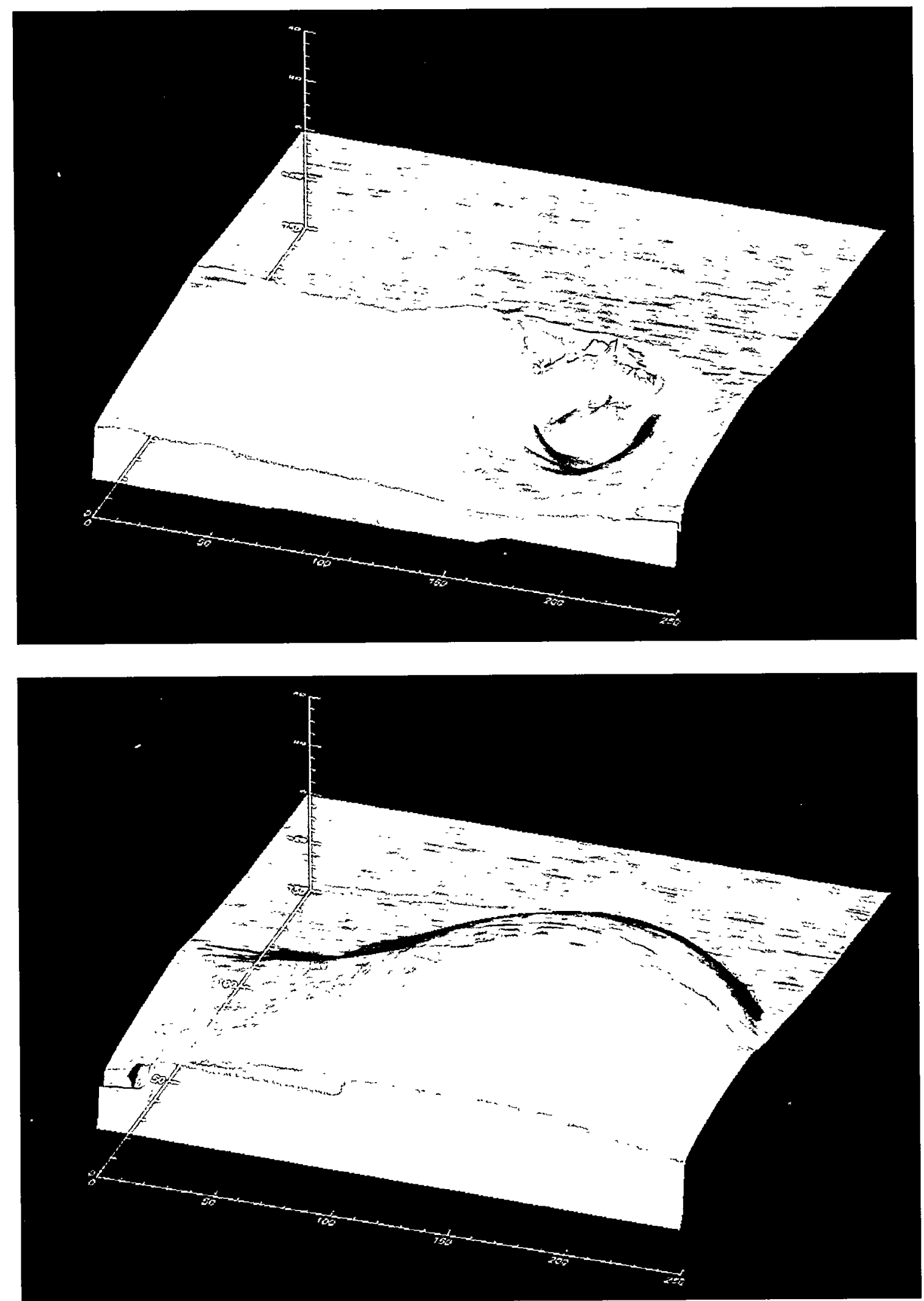
W-TRT-A-00002

Page 25 of 36
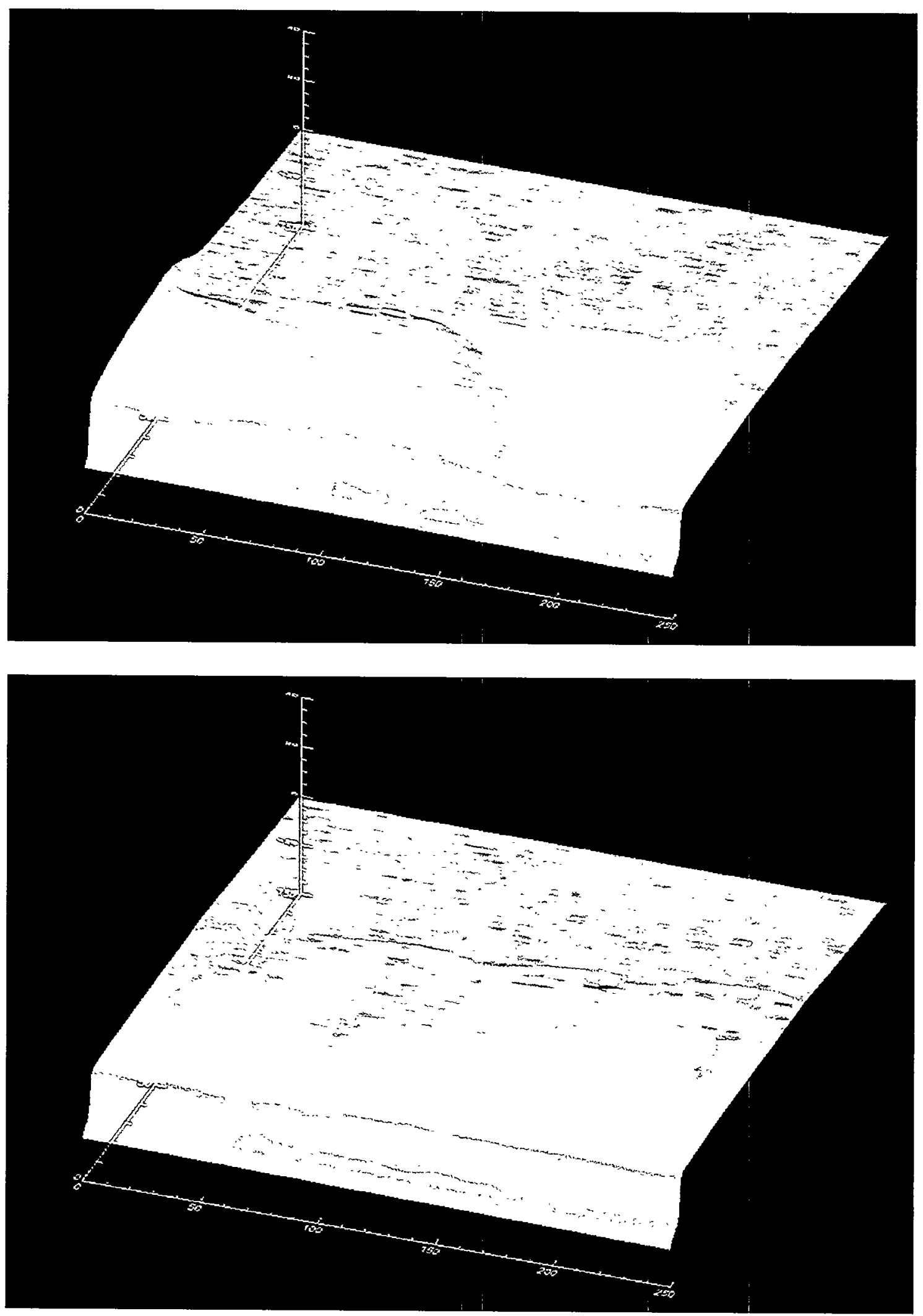
W-TRT-A-00002

Page 26 of 36
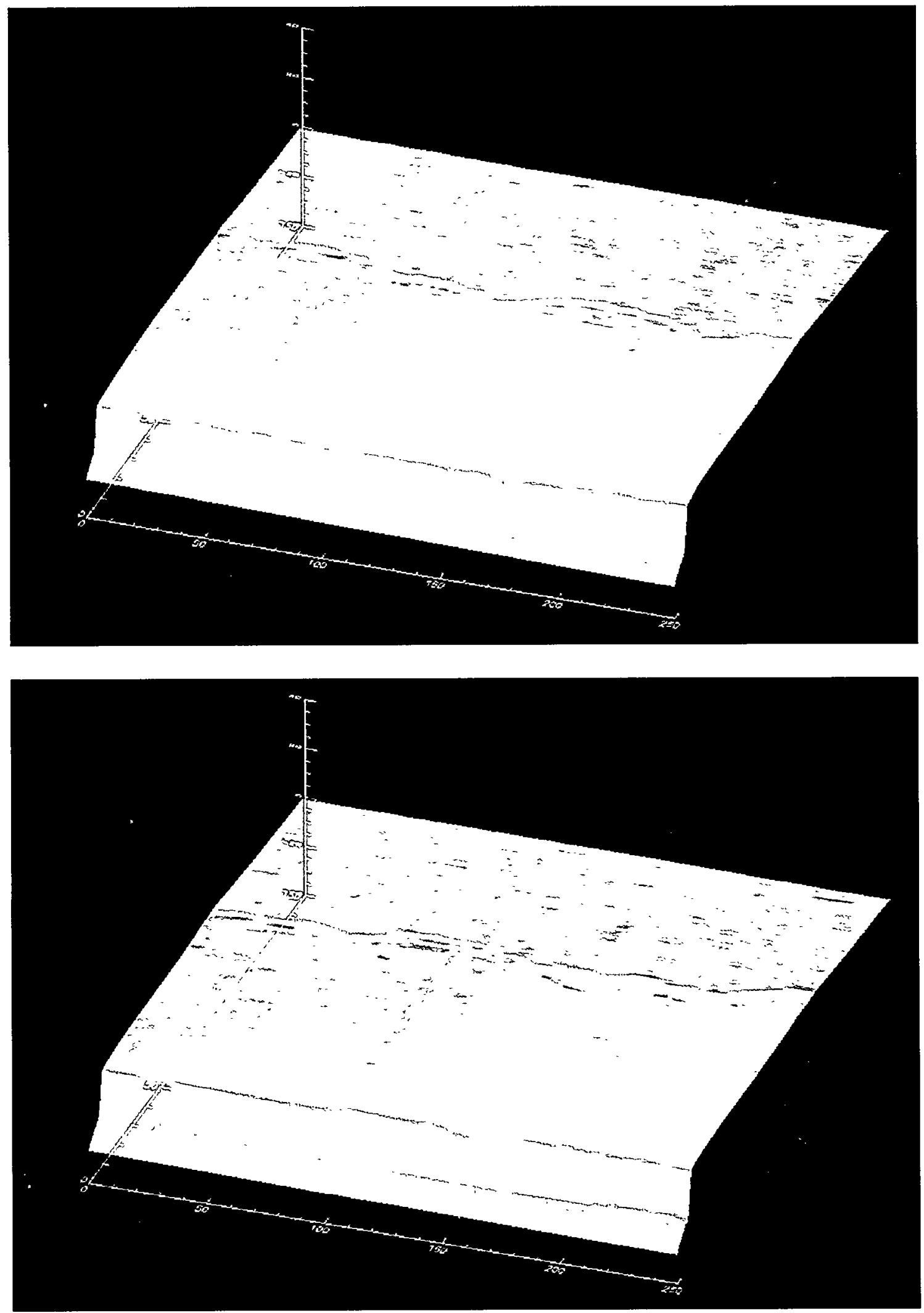

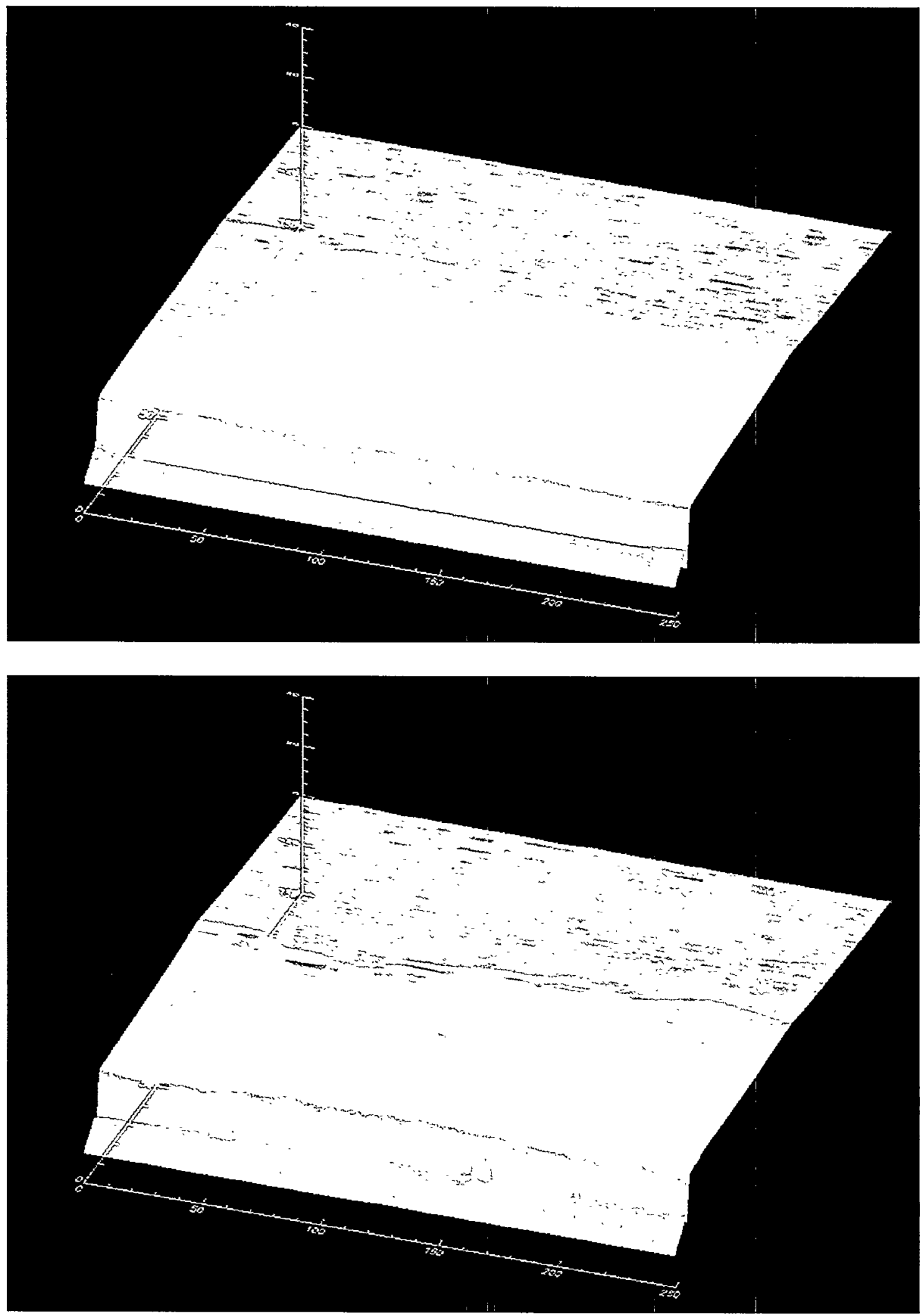

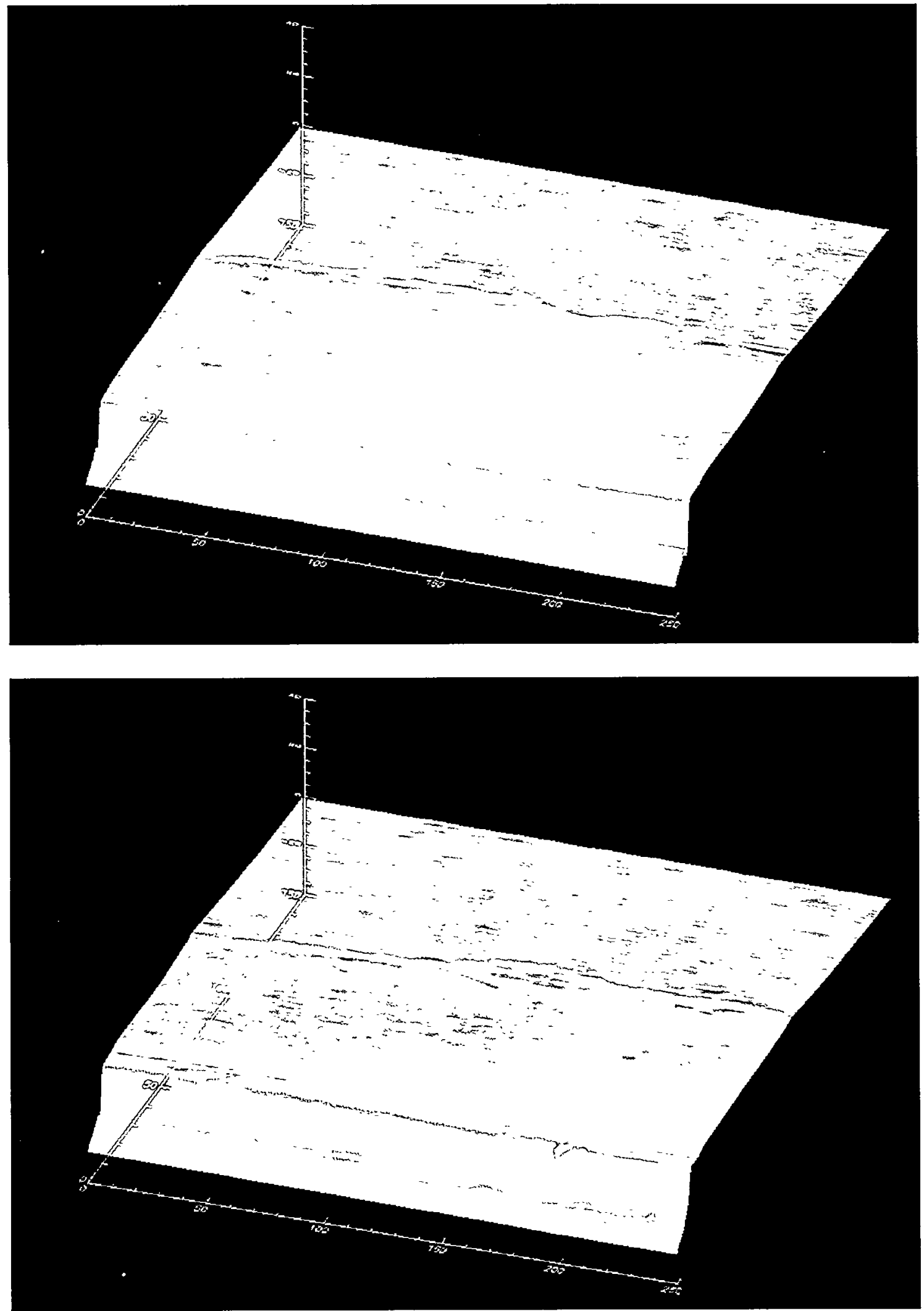
Page 29 of 36
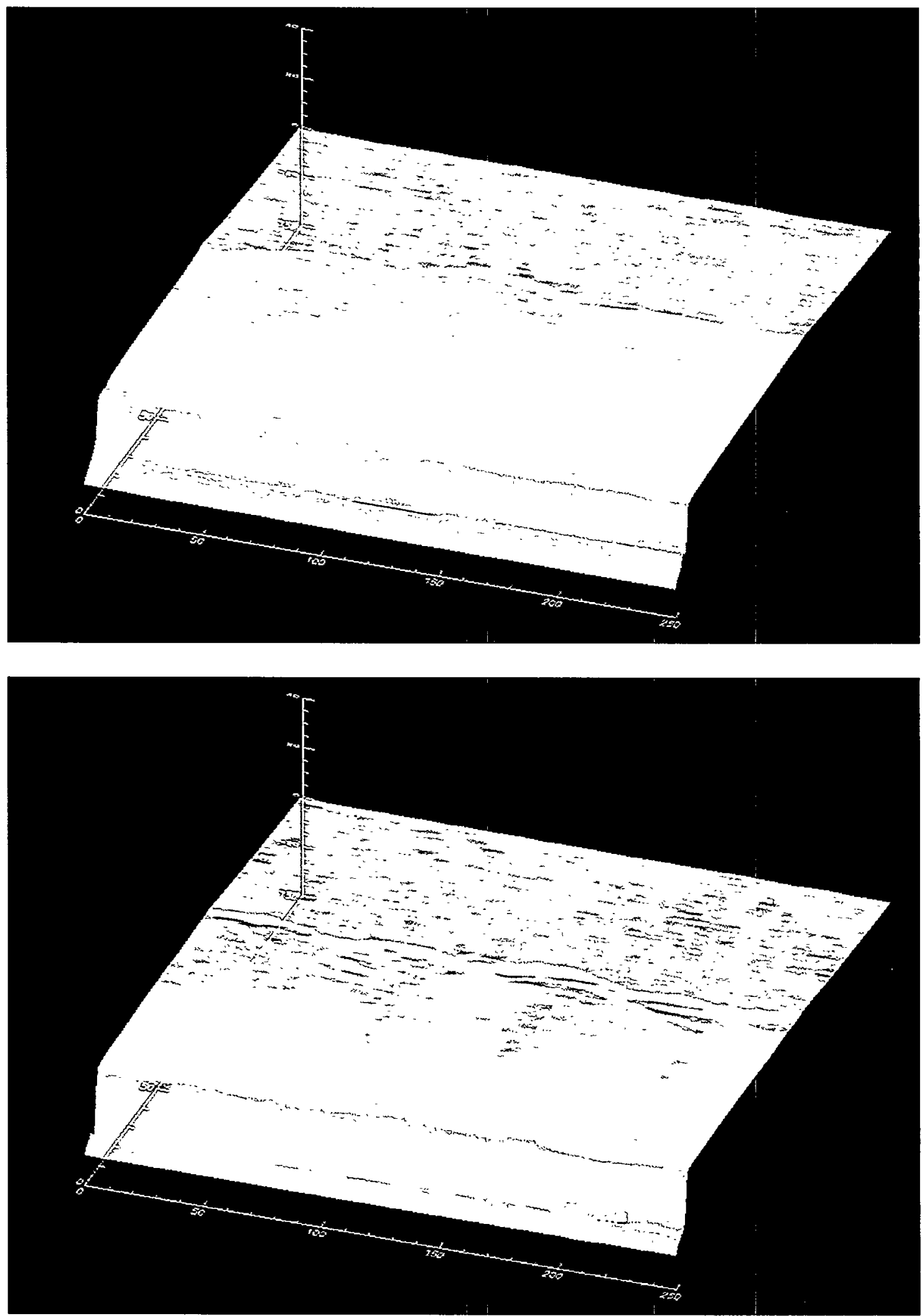

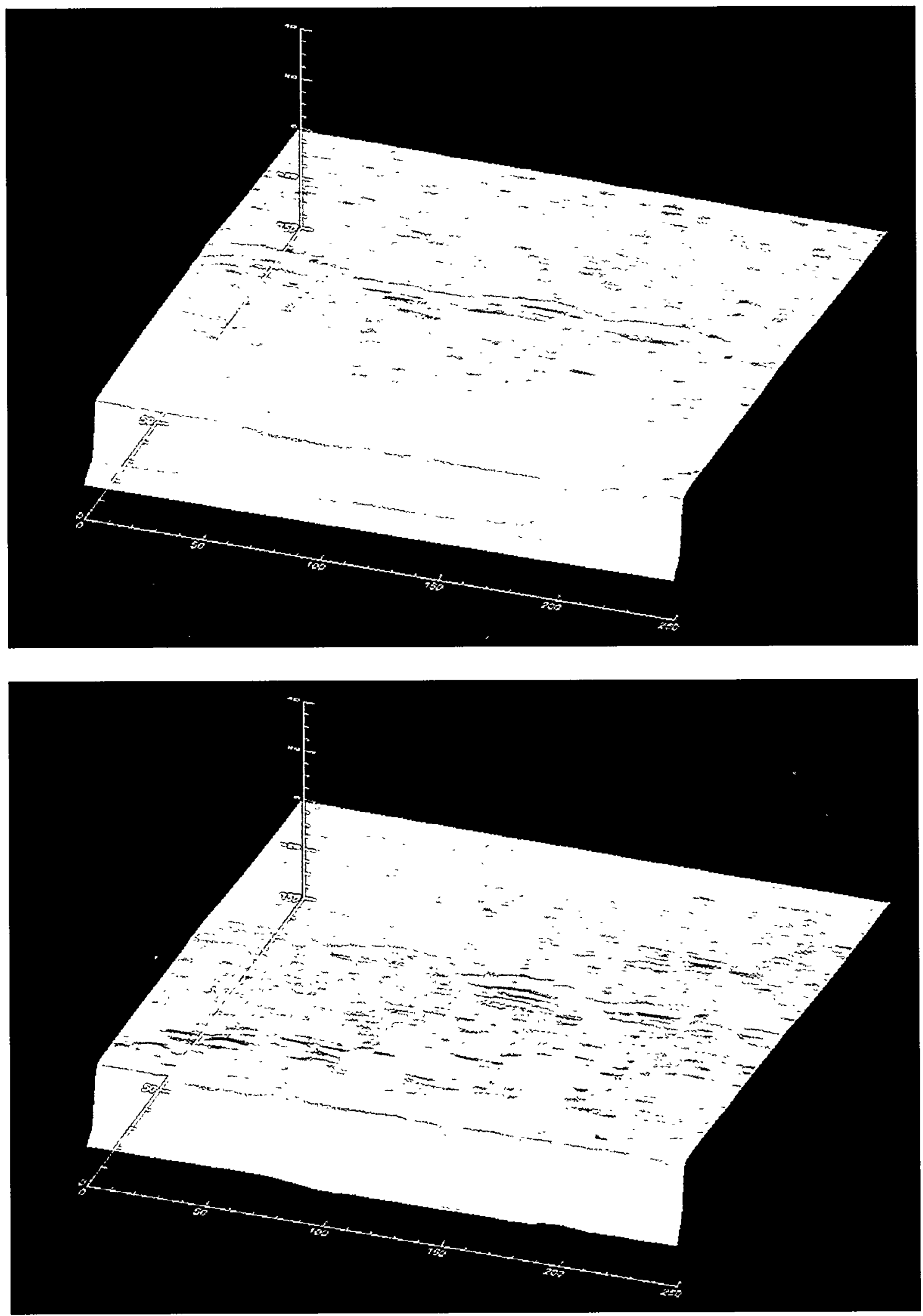

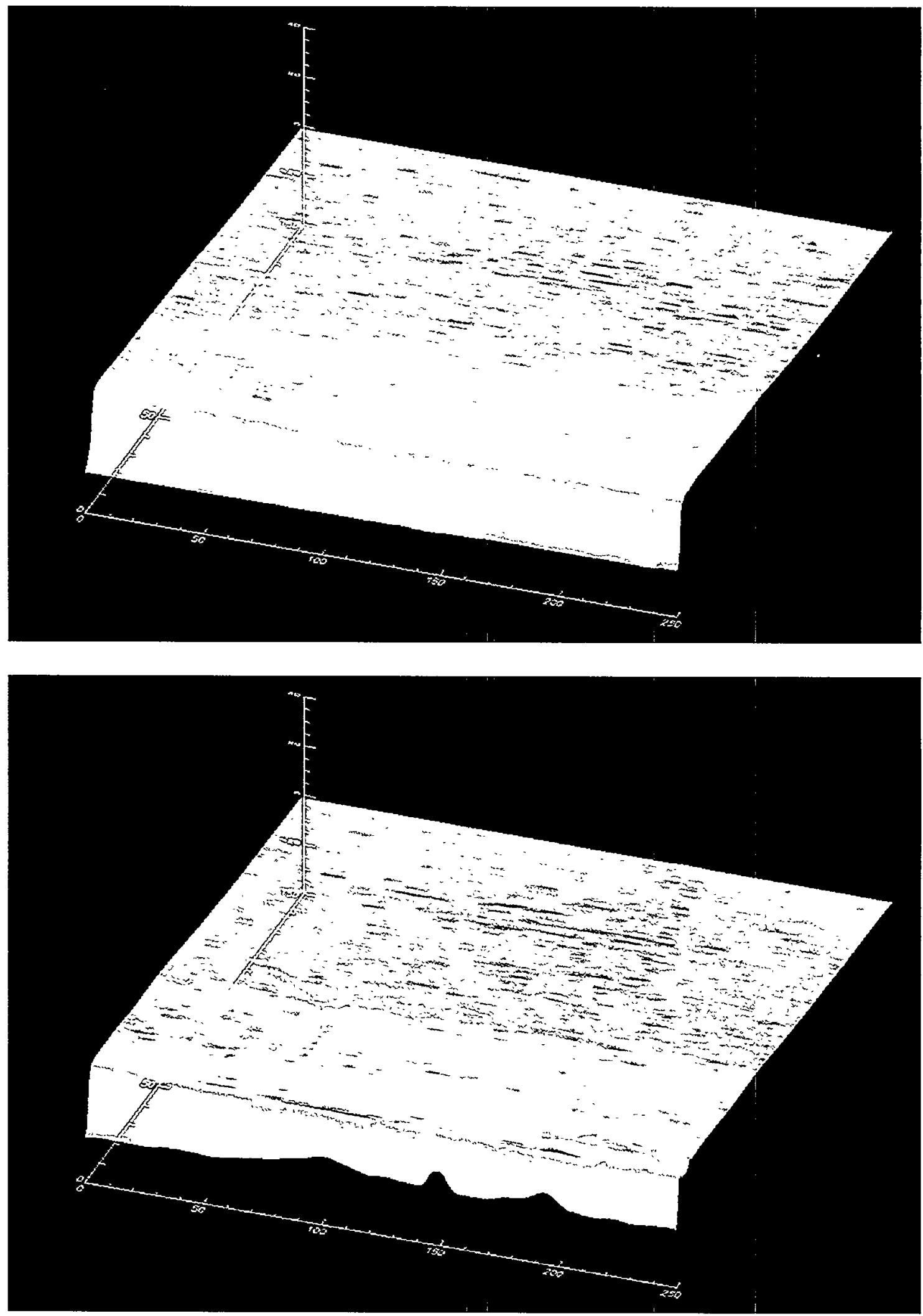
W-TRT-A-00002

Page 32 of 36
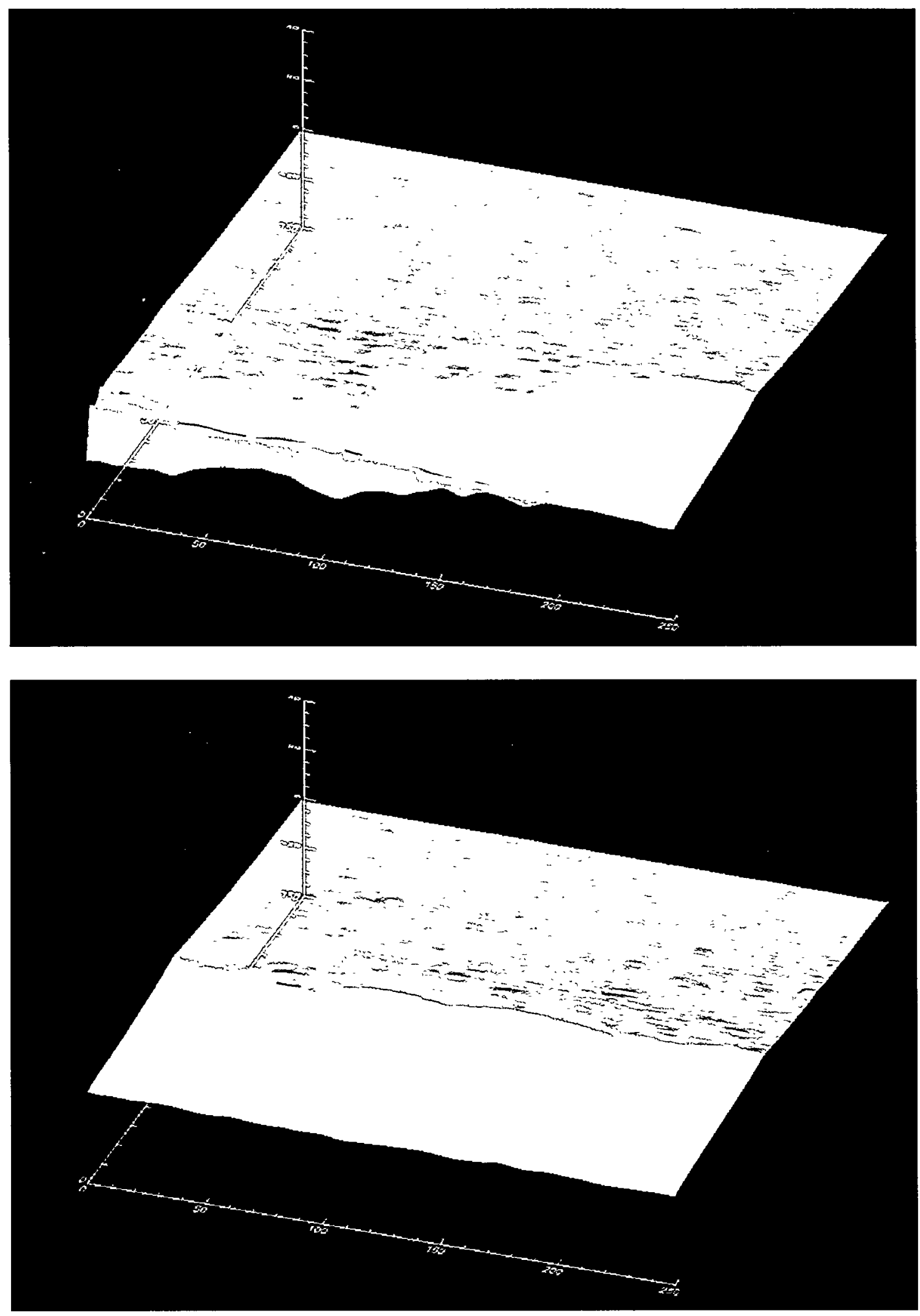

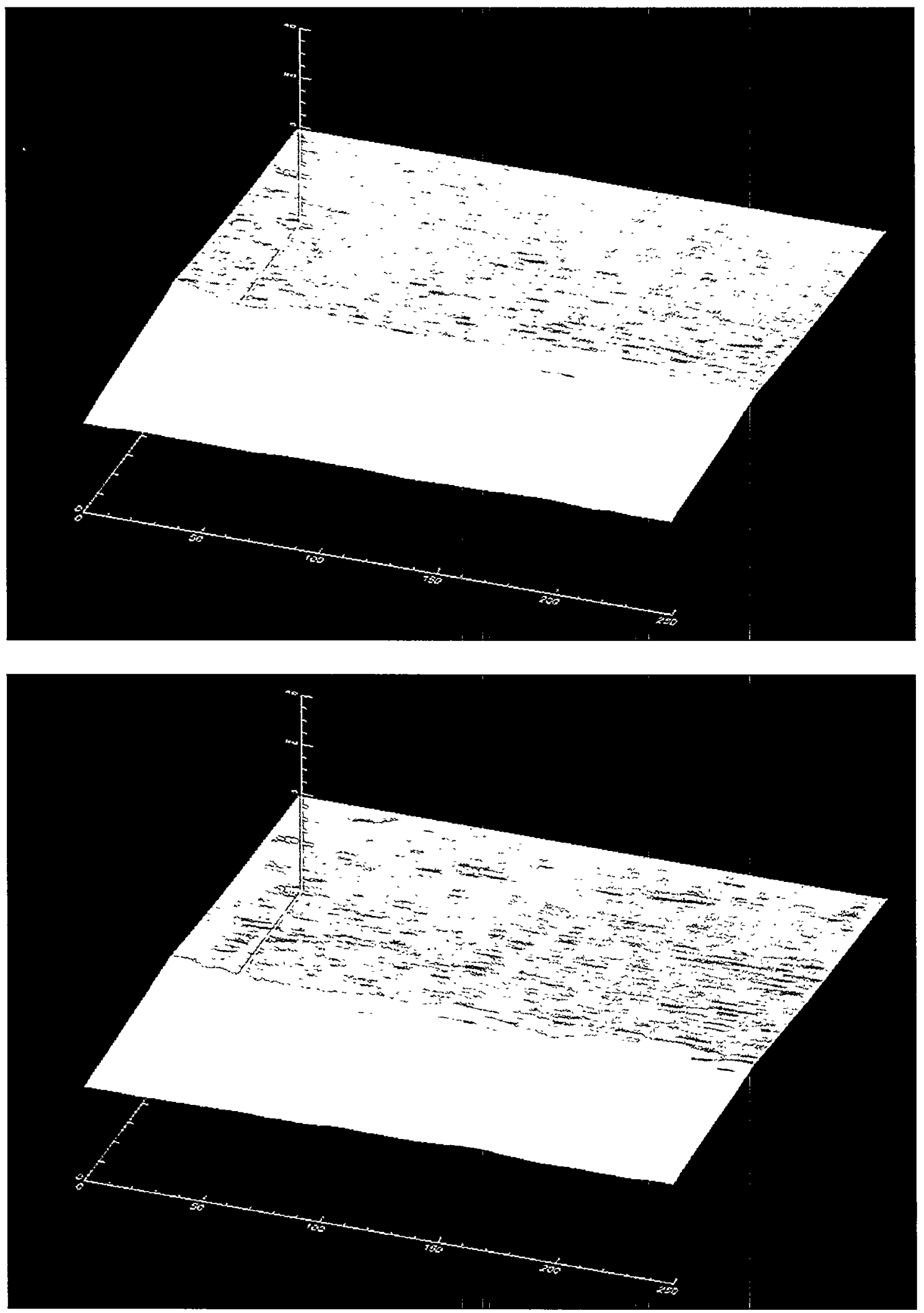
W-TRT-A-00002

Page 34 of 36
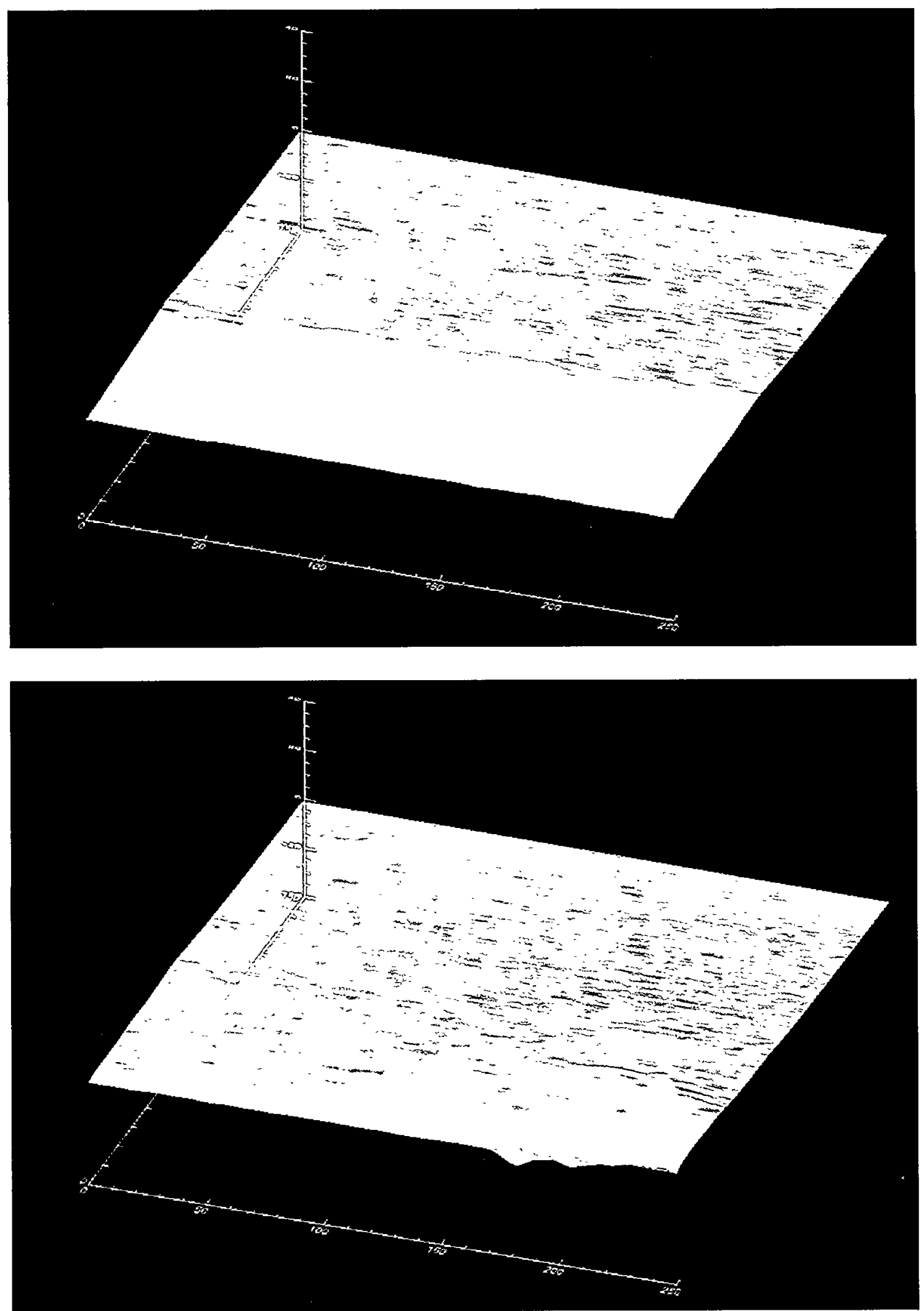

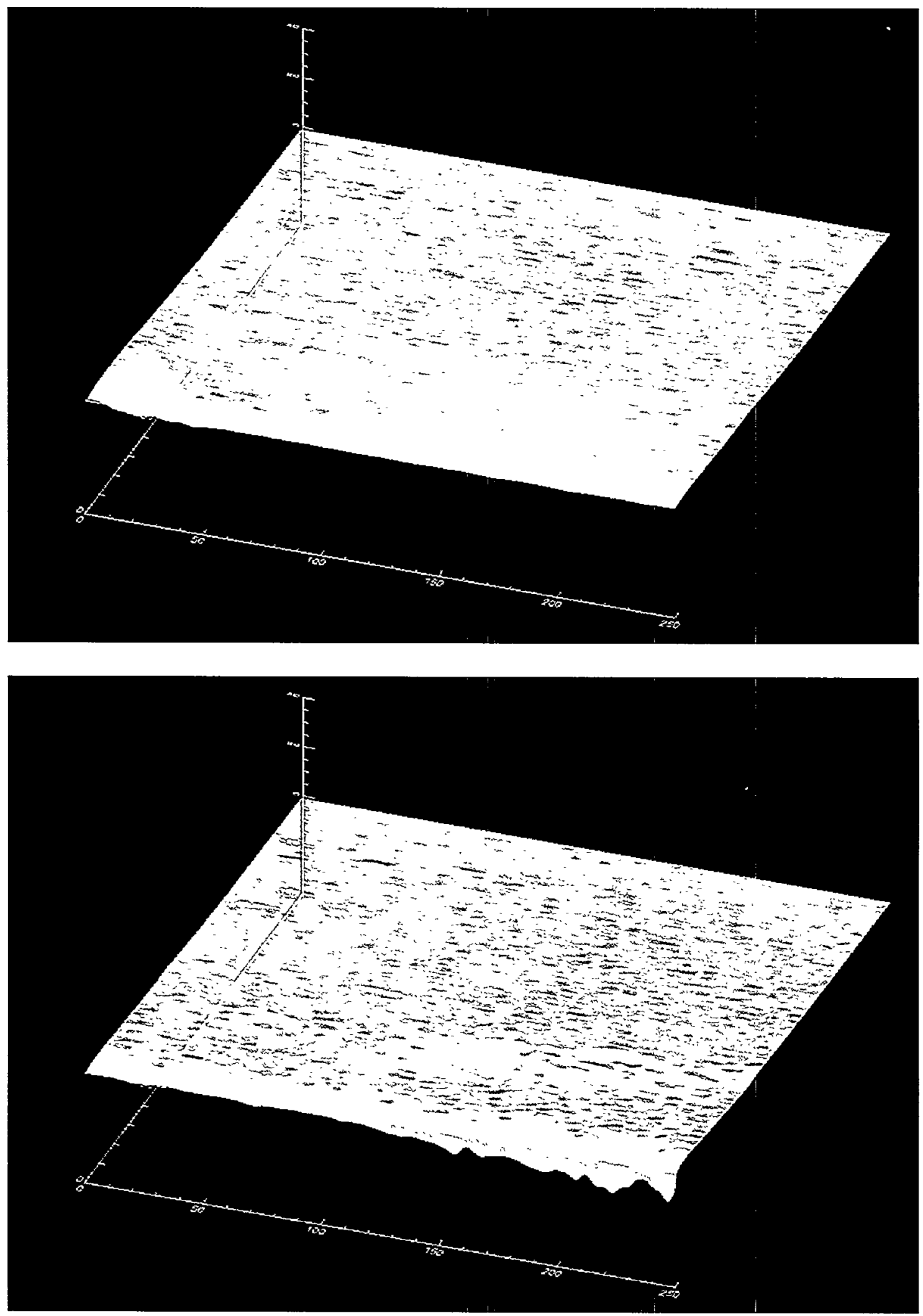


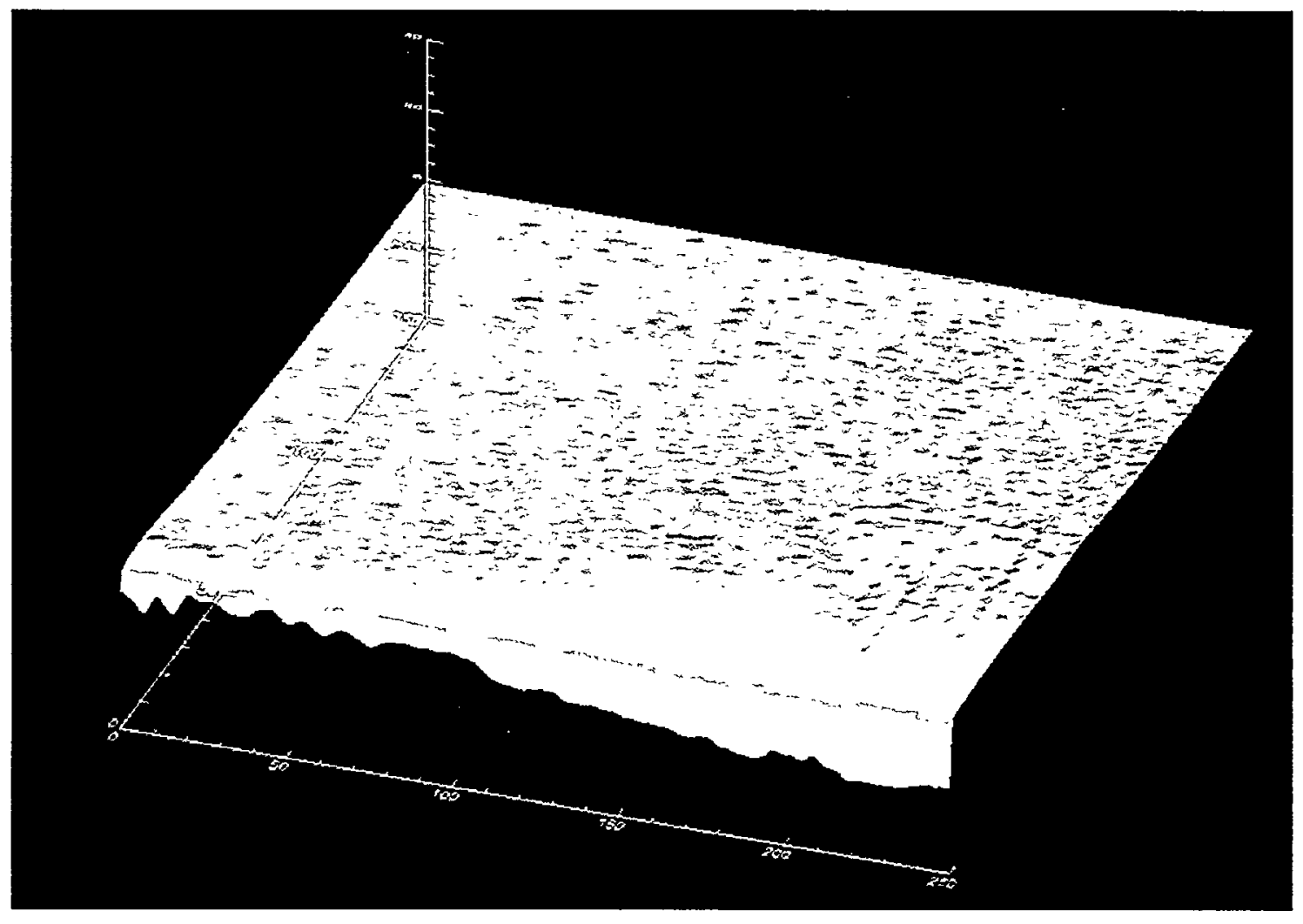




\section{Distribution:}

W. E. Lloyd, Jr., 221-F

W. P. Martin, 221-F

W. L. Rigot, Jr., 221-F

E. R. Seldon, 703-F

M. A. Smith, 703-46A

E. L. Wilmot, 246-H

N. C. McFall, 703-F

R. N. Robinson, 703-F

R. H. Haynes, 703-F

R. E. Felt. 707-7F

C. H. Keilers, 719-14A

C. E. Armitage, 703-F

J. Greggi, Jr., 707-F

W. E. Harris, 704-2H

C. P. Wolfe, 773-A

J. D. Cohen, 773-A

W. I. Lewis, 773-A

S. L. Tibrea, 773-A

N. C. Iyer, 773-41 A

J. W. Wong, 773-A

R. L. Bickford. 730-A

S. L. West. 773-A

S. R. Salaymeh, 773-41A

J. A. Marra, 730-A

J. C. Whitehouse, 723-A

M. W. Loibl, 730-A

C. E. Sessions. 730-A

W. L. Daugherty, 730-A

J. P. Gray, 730-A

D. N. Maxwell, 730-A

B. D. Howard, 730-A

G. E. Weeks. 305-IA

D. Z. Nelson. 773-A

M. E. Summer, 773-A

D. J. Trapp, 723-A

K. P. Klapper, 773-A

M. L. Rogers, 723-A

D. J. Shull. 723-A

C. G. Brown. 773-A

T. M. Stefek. 723-A

L. A. ReFalo, 305-A

730-A Document Control, Job Folder 22751 